\title{
RIDING SUCCESSIVE PRODUCT DIFFUSION WAVES. BUILDING A TSUNAMI VIA UPGRADE-REBATE PROGRAMS*
}

\author{
Vardan Avagyan $^{1}$, Mercedes Esteban-Bravo ${ }^{2}$ and José M. Vidal-Sanz ${ }^{3}$
}

\begin{abstract}
We discuss how trade-in rebates can be used to manage product multigenerational innovation diffusion waves, and study the optimal behavior of the firm controlling the prices and rebates associated to product upgrades. We show how this strategy accelerates the diffusion and can lead to profit increments of about 5\%. The strategy is profitable even when the rebate subsidizes the upgrades entirely.
\end{abstract}

Keywords: New Product Diffusion, Successive Generations, Trade-in, Upgrades, Optimal Strategies.

\footnotetext{
* Research funded by two research projects, by the Comunidad de Madrid and the Spanish Government.

${ }^{1}$ Vardan Avagyan, Department of Business Administration, University Carlos III de Madrid, C/ Madrid 126, 28903 Getafe (Madrid), Spain; tel: +34 91624 8921; fax: +34 91624 8921; e-mail: vavagyan@emp.uc3m.es

${ }^{2}$ Mercedes Esteban-Bravo, Department of Business Administration, University Carlos III de Madrid, C/ Madrid 126, 28903 Getafe (Madrid), Spain; tel: +34 91624 8921; fax: +34 91624 8921; e-mail: mesteban@emp.uc3m.es

3 Jose M. Vidal-Sanz, Department of Business Administration, University Carlos III de Madrid, C/ Madrid 126, 28903 Getafe (Madrid), Spain; tel: +34 91624 8642; fax: +34 91624 9607; e-mail: jvidal@emp.uc3m.es
} 


\section{Introduction}

In this paper we study how to manage sales of durable new products under successive generation diffusion waves with trade-in rebates. If the durability of the product is large relative to the introduction times of successive generations, they cannibalize each other as firms often sell inventory of old generation goods which were leftover from previous periods simultaneously with newer ones. The older generations are often perceived to be of lower quality, and firms usually sell it at a reduced price (Koenigsberg, and Ferguson, 2007). Some potential customers from the old generation can upgrade to new one, but others could buy the old one at a lower price, and this can affect a large share of customers. The innovation diffusion literature has suggested that fear of obsolescence may cause some consumers to refuse to buy technological products from the first generations (Cohen et al. 1996; Dhebar 1996; Venkatesh and Brown 2001), waiting for new products and accumulate old potential buyers for new generations (Putsis 1993). Secondary markets for used durable goods reduce consumers threat of leapfrogging, but on the other hand generate additional competition from old products that reenter the market (Desai, Koenigsberg, and Purohit, 2007). Some companies buy-back in second-hand markets and remanufacture the product gaining a competitive advantage (Heese et al., 2005). Upgrade-Rebates can also be used to disable a secondhand market for the old versions, using buybacks to retire the old units from the market (see Levinthal and Purohit, 1989).

Managing diffusion waves for successive product generations implies that marketing managers should try to dissuade some customers to jump across successive generation waves optimally for the company profits. In addition companies should consider some strategy to lessen the regret of consumers who have bought old-generation products and persuade them to upgrade to new generations in the future (Dhebar 1996). In this paper we discuss how Upgrade-Rebates (also known as trade-in rebates) can be used to reintegrate owners of old versions of the product to the market and therefore increase current sales. An upgrade-rebate program allows customers who own an old generation version of the product to trade it in for a product belonging to a later generation at a discounted price. This is also an instrument to make a credible threat that if the consumers do not buy the first generation product, they will face a relatively higher price for the new product in subsequent generations. A successful trade-in promotion can accelerate the diffusion of first generations.

Upgrade-rebates are implemented by companies in different industries such as software, electrical appliances, cars, etc. For instance, currently Hewlett-Packard allows its customers to trade-in different types of products and brands for its new HP products ${ }^{1}$. Xerox provides up to $\$ 600$ rebate to trade in old product of own and competitive brands for its new product models ${ }^{2}$. Similar strategies are also implemented by Motorola and Sony, among others. Governments often adopt similar strategies. Some examples are the Car Allowance Rebate System (CARS) program launched out by US Congress to increase automotive sales and aid the environment and the Home Renovation Rebate in Canada in the form of a tax credit.

Trade-ins can be considered as a strategic link between reverse and direct channels management, where the customer bears part of the reverse-logistics and the returned product is not remarketed (see Ray, Boyaci and Aras, 2005). Upgrade-rebates have been considered from a pricing perspective. Notice that new customers pay more than those who upgrade an old product, and these rebates can be thought of as a price discrimination based on consumers' purchase history. This has been studied by Lee and Lee (1998), Levinthal and Purohit (1989) in second hand markets and Fudenberg and Tirole (1998) in a more general setup. Ackere and Reyniers (1995) consider quasidurable goods. But in these models the results depend heavily on parametric assumptions, generally in a two-period framework. The rich dynamic perspective, where upgrade-rebates are used to control the whole diffusion of successive generations, is hitherto unexplored. In this paper we study this problem in a context without a second-hand market, and compute the optimal rebates policy to ride the successive diffusion waves.

The organization of the remainder of the paper is the following. In the next section we present a general model of successive product generations diffusion, the inclusion of the upgrade-rebate program into the benchmark model, and the optimal solution of the problem. In Section 3 we provide some simulations with numerical solutions and results. Finally, we conclude the paper with general discussion, pointing out some limitations and suggestions for future research.

\footnotetext{
${ }^{1}$ http://www.hp.com/united-states/tradein/home_flash.html

${ }^{2}$ http://xerox.tradeups.com/Customers/17/Default.aspx
} 


\section{A Successive Generations Diffusion Model}

In this section we present a diffusion model for successive product generations. We build up on previous work on successive generation models, such as Norton and Bass, (1987, 1992), Mahajan and Muller (1996), and Stremersch, Muller and Peres (2010). We first introduce the benchmark model without upgrade-rebates, and then we discuss how the model can accommodate this type of promotion.

\subsection{The Benchmark Model}

Let us consider $K$ product generations, the $i-t h$ one is introduced at time $\tau_{i}$ with a market potential $m_{i}$. After the entry of generation $i$, the older generations $j<i$ can still continue to acquire some customers from $m_{j}, m_{j-1}, m_{j-2}, \ldots, m_{1}$, but more importantly, the new generation attracts natural upgraders from the older generations $m_{i-1}, m_{i-2}, \ldots m_{1}$. The expression of natural upgraders is used to point out that they are not attracted by a promotion, but are those which would have bought the old generation had the new generation(s) not been introduced. The model allows leapfrogging (i.e. upgrading beyond the subsequent generation) and the specification can be easily adapted to durable and non durable products. In particular, for non-durable products we consider sales defined as

$$
\begin{aligned}
\left(\begin{array}{c}
S_{1}(t) \\
S_{2}(t) \\
\vdots \\
S_{K}(t)
\end{array}\right) & =\left(\begin{array}{cccc}
f_{11}(t) & 0 & \ldots & 0 \\
f_{12}(t) & f_{22}(t) & \ldots & 0 \\
\vdots & \vdots & \ddots & \vdots \\
f_{1 K}(t) & f_{2 K}(t) & \ldots & f_{K K}(t)
\end{array}\right)\left(\begin{array}{c}
m_{1} \\
m_{2} \\
\vdots \\
m_{K}
\end{array}\right) \Leftrightarrow \\
\mathbf{S}(t) & =\mathbf{f}(t)^{\prime} m
\end{aligned}
$$

where $m=\left(m_{1}, \ldots, m_{K}\right)^{\prime}$, and $\mathbf{f}(t)$ is a diffusion matrix with generic element $f_{i j}(t) \in(0,1)$ describing the proportion of potential customers from $m_{i}$ purchasing product from generation $j$ at time $t$. Obviously $f_{i i}(t)$ is the net penetration of generation $m_{i}$ at time $t$ removing the upgraders. The transposed diffusion matrix $\mathbf{f}(t)^{\prime}$ is lower triangular to ensure that old generation products do not attract customers from the new generations, and the elements of each column of $\mathbf{f}(t)^{\prime}$ sum less than one (i.e., $\sum_{j=i}^{K} f_{i j}(t) \leq 1$ for all $i=1 \ldots K)$, to ensure that the summation of sales drawn from potential customers of generation $i$ do not exceed the potential market ceiling $m_{i}$. It implies that $\sum_{j=i}^{K} \dot{f}_{i j}(t) \leq 0$ for all $i=1 \ldots K$.

This is a flexible structure, and several specifications can be considered for $\dot{f}_{i j}$. In particular, we consider that the the departing rate from potential customers of generation $i$ to purchase product generation $j$ is given by

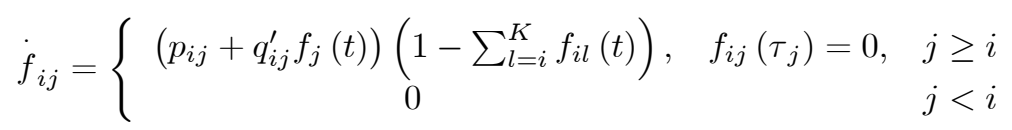

where $f_{j}(t)=\left(f_{1 j}(t), \ldots, f_{j j}(t), 0, \ldots, 0\right)^{\prime}$ is the column $j$ of matrix $\mathbf{f}(t)$ and $q_{i j}$ is a vector with all the coefficients equal to zero after row $j$, meaning that the upgrading from $i$ to $j$ is accelerated when $f_{j j}$ is high and when more people upgrade from old generations to $j$. The $\left(1-\sum_{l=i}^{K} f_{i l}(t)\right)$ factor ensures that the columns of $\mathbf{f}(t)^{\prime}$ total at most 1 at any time. Notice that we can consider more complex structures for defections in this market, e.g. considering a generation 0 , with $S_{0}(t)$ the number of defections and a row $f_{j 0}(t)$ in $\mathbf{f}(t)^{\prime}$ accounting for the attractions from all generations to this event.

The previous model is appropriated for non-durable products so that the adopters $\mathbf{f}(t)^{\prime} m$ at time $t$ are the current sales (except for the defections, if they had been considered). If instead of non-durables we model the diffusion of durable products, we can simply replace (1) by the expression

$$
\mathbf{S}(t)=\dot{\mathbf{f}}(t)^{\prime} m
$$

meaning that sales at time $t$ are given by the change in penetration rates weighted by the market potentials. Notice that the vector $\mathbf{f}(t)^{\prime} 1$ is the penetration percentage of each generation at time $t$. In both cases, durables and non-durables, we can introduce controls on the diffusion matrix $\mathbf{f}(t)$ analogously to the Horsky 
and Simon (1983) model, or multiplicatively when these controls also affect the market potentials $m$. Note also that semi-durables could be handled in the benchmark setting

$$
\mathbf{S}(t)=\dot{\mathbf{f}}(t)^{\prime} m+\int_{0}^{t} \dot{\mathbf{f}}(s)^{\prime} m \Delta(t-s) d s
$$

where $\Delta(\tau)=\operatorname{dig}\left\{\Delta_{i}(\tau)\right\}$ is a diagonal matrix with the probabilities of a product of generation $i$ perishing after $\tau$ periods.

\subsection{The Model With an Upgrade-Rebate Program}

Let us define $r(t)$ as the cumulative Upgrade-Rebate matrix, i.e. the element $r_{i j}(t) \in(0,1)$ is the fraction of individuals owning a product from generation $i$ who have upgraded it to a product of generation $j$ by time $t$. The fraction of individuals upgrading at time $t$ is $\dot{\mathbf{r}}(t)$. These matrices are lower triangular, as not all types of upgrades are pursued by the company, for example

$$
\mathbf{r}(t)^{\prime}=\left(\begin{array}{cccc}
0 & 0 & \ldots & 0 \\
r_{12}(t) & 0 & \ldots & 0 \\
\vdots & \vdots & \ddots & \vdots \\
r_{1 K}(t) & r_{2 K}(t) & \ldots & 0
\end{array}\right)
$$

if the company just allows changes from old generation purchases to new generations and not vice versa. In practice, these matrices are often spare as just a few elements are non-zero as only upgrades between consecutive generations are allowed, but allowing most of the old trade-up pair combinations the optimization analysis is more flexible. Similar to the benchmark model, the elements of each column of $\mathbf{r}(t)$ sum at most one (i.e., $\sum_{j=i+1}^{K} r_{i j}(t) \leq 1$ for all $\left.i=1 \ldots K\right)$, to ensure that the summation of upgraders from generation $i$ to other generations does not exceed one, this implies that $\sum_{j=i+1}^{K} \dot{r}_{i j}(t) \leq 0$ for $i=1 \ldots K$. Once again this is a flexible structure, and several specifications can be considered for $\dot{r}_{i j}$. In particular, we can consider that for $j>i$

$$
\begin{aligned}
r_{i j}(t) & =\left(\gamma_{i j}+\beta_{i j}^{\prime} r_{j}(t)\right)\left(1-\sum_{l=i+1}^{K} r_{i l}(t)\right) \phi_{i j} D_{i j}(t) \\
r_{i j}\left(\tau_{j}\right) & =0 .
\end{aligned}
$$

and $\dot{r_{i j}}(t)=0$ for $i>j$, where $r_{j}(t)=\left(r_{1 j}(t), \ldots, r_{(j-1) j}(t), 0, \ldots, 0\right)^{\prime}$ is the column $j$ of matrix $\mathbf{r}(t)$, and $D_{i j}(t) \geq 0$ are rebates obtained on the purchase of $j$ when the product $i$ is returned.

The diffusion $\mathbf{f}(t)$ of the different generations will be affected by the upgrades $\mathbf{r}(t)$. The upgrade-rebate program also provides a response to the consumers threat of leapfrogging, and the customers who use a rebate can also use word-of-mouth in a different way than those who do not upgrade through this promotion. In particular we replace (2) by,

$$
\dot{f}_{i j}=\left(p_{i j}+q_{i j}^{\prime} f_{j}(t)+r_{j}(t)^{\prime} f(t) b_{i j}\right)\left(1-\sum_{l=i}^{K} f_{i l}(t)\right)\left(1-\theta_{i j} P_{j}(t)\right),
$$

for $j \geq i$ and $f_{i j}=0$ when $j<i$, with $f_{i j}\left(\tau_{j}\right)=0$, where $q_{i j}$ is a column vector with all the coefficients equal to zero after row $j, P_{j}(t)$ are prices of generation $j$, and $b_{i j}$ is a column vector with zero elements after $j$. For simplicity, we assume multiplicative linear prices (e.g. Dockner and Jorgensen 1988).

Next we discuss the sales behavior. Recall that $\mathbf{f}(t)^{\prime} m$ is the vector of cumulated sales from the different generations up to time $t$. The cumulative sales caused by the Upgrade-Rebate Program at time $t$ are (as a column including all generation):

$$
\begin{aligned}
\mathbf{r}(t)^{\prime} \mathbf{f}(t)^{\prime} m & =\int_{0}^{t}\left(\dot{\mathbf{r}}(s)^{\prime} \mathbf{f}(s)^{\prime} m+\mathbf{r}(s)^{\prime} \dot{\mathbf{f}}(s)^{\prime} m\right) d s \\
& =\int_{0}^{t}\left(\begin{array}{c}
\mathbf{f}(s) \dot{\mathbf{r}}(s)+\mathbf{f}(s) \mathbf{r}(s))^{\prime} m d s,
\end{array}\right.
\end{aligned}
$$


(the proof is immediate as $\int_{0}^{t}(\mathbf{f}(s) \dot{\mathbf{r}}(s))^{\prime} m d s=(\mathbf{f}(t) \mathbf{r}(t))^{\prime} m-\int_{0}^{t}(\dot{\mathbf{f}}(s) \mathbf{r}(s))^{\prime} m d s$ integrating by parts). Therefore, the instantaneous Upgrade-Rebate sales at time $t$ is the derivative of $\mathbf{r}(t)^{\prime} \mathbf{f}(t)^{\prime} m$ which is equal to $(\mathbf{f}(t) \dot{\mathbf{r}}(t)+\mathbf{f}(t) \mathbf{r}(t))^{\prime} m$; i.e. those types of current sales are decomposed as the sum of sales to old buyers who upgrade now $\dot{\mathbf{r}}(t)^{\prime} \mathbf{f}(t)^{\prime} m$, and sales of current buyers of old versions who immediately choose to upgrade $r(t)^{\prime} \mathbf{f}(t)^{\prime} m$. In order to ban immediate upgrades some companies could consider a constrained rebate structured with $r(t)$ orthogonal to $\mathbf{f}(t)$, but this could be suboptimal and we will not impose it in our basic structure.

Finally, the total sales at time $t$ in all product generations are the sum of regular sales of the durable products as in (3), and the second summand has sales drawn from the Upgrade-Rebate promotion

$$
S(t)=\dot{\mathbf{f}}(t)^{\prime} m+(\mathbf{f}(t) \dot{r}(t)+\dot{\mathbf{f}}(t) r(t))^{\prime} m
$$

The company profits at time $t$ are

$$
\begin{aligned}
\Pi(t)= & m^{\prime}(\dot{\mathbf{f}}(t)+\mathbf{f}(t) \dot{r}(t)+\dot{\mathbf{f}}(t) \mathbf{r}(t))(P(t)-c(t)) \\
& -m^{\prime}(\mathbf{f}(t) \mathbf{D}(t) \dot{r}(t)+\mathbf{f}(t) \mathbf{D}(t) \mathbf{r}(t)) \mathbf{1}
\end{aligned}
$$

where $\mathbf{D}(t)$ is the rebates matrix and $(P(t)-c(t))$ is a vector with the unit margins for each generation and $\mathbf{1}$ is a vector of ones.

\subsection{The optimal behavior}

Assuming a durable-goods monopolist who controls the diffusion of all the generations, the company profits are obtained by maximizing:

$$
\begin{aligned}
\Pi= & \int_{0}^{\infty} e^{-r t} \Pi(t) d t \\
= & \int_{0}^{\infty} e^{-r t}\left(m^{\prime}(\dot{\mathbf{f}}(t)+\mathbf{f}(t) \dot{r}(t)+\dot{\mathbf{f}}(t) \mathbf{r}(t))(P(t)-c(t))\right. \\
& \left.-m^{\prime}(\mathbf{f}(t) \mathbf{D}(t) \dot{\mathbf{r}}(t)+\mathbf{f}(t) \mathbf{D}(t) \mathbf{r}(t)) \mathbf{1}\right) d t
\end{aligned}
$$

subject to the state equations and the initial values $f_{i j}\left(\tau_{j}\right)=r_{i j}\left(\tau_{j}\right)=0$ for each $i \leq j$.

In order to write the first-order conditions of the optimal control problem, it is convenient to write all the state variables as vectors instead of matrices. We define $f, \dot{r}_{t}, f_{t}, r_{t}, D_{t}$ the half-vectorization ${ }^{3}$ of matrices $\mathbf{f}(t), \dot{\mathbf{r}}(t), \mathbf{f}(t), \mathbf{r}(t), \mathbf{D}(t)$, respectively; introducing a compact notation for profits and state equations,

$$
\begin{aligned}
\Pi_{t} & =\Pi\left(f_{t}, r_{t}, P_{t}, D_{t}\right) \\
\dot{f}_{t} & =\psi\left(f_{t}, r_{t}, P_{t}\right) \\
\dot{r}_{t} & =\rho\left(f_{t}, r_{t}, D_{t}\right) .
\end{aligned}
$$

Let the Hamiltonian function $H$ of the optimal control be given by:

$$
H_{t}\left(f_{t}, r_{t}, P_{t}, D_{t}, \lambda_{t}, \mu_{t}\right)=\Pi\left(f_{t}, r_{t}, P_{t}, D_{t}\right)+\lambda_{t} \cdot \psi\left(f_{t}, r_{t}, P_{t}\right)+\mu_{t} \cdot \rho\left(f_{t}, r_{t}, D_{t}\right),
$$

\footnotetext{
${ }^{3}$ The vectorization of an $n \times m$ matrix $A$, denoted by vec $(A)$, is the $n m \times 1$ column vector obtain by stacking the columns of the matrix A on top of one another proceeding from column 1 to column $m$. The half-vectorization $v e c h(A)$ of a $n \times n$ matrix $A$ is the $n(n+1) / 2 \times 1$ column vector obtained by vectorizing only the lower triangular part of $A$, i.e. staking the low-triangle part of the columns on top of one another from column 1 to $m_{4}$
} 
where $\lambda_{t}$ and $\mu_{t}$ be the multiplier vectors associated with the state variables $f_{t}$ and $r_{t}$, respectively. The maximum principle conditions are (in compact notation)

$$
\begin{array}{ll}
\frac{\partial H_{t}}{\partial D_{t}}=0, \quad \frac{\partial H_{t}}{\partial P_{t}}=0 & \text { for any } i<j, \\
\dot{\lambda}_{t}=-\frac{\partial H_{t}}{\partial t_{t}}, & \text { for any } i \leq j, \\
\dot{\mu}_{t}=-\frac{\partial H_{t}}{\partial r_{t}} & \text { for any } i<j,
\end{array}
$$

together with initial conditions at introduction times $\tau_{i}$, and transversality conditions of $\lambda_{t}, \mu_{t}$ tending to zero (numerically we equalize them to zero for large $t$ ). Also, we require that the marginal valuation of the state variable(s) be the same evaluated before and after each $\tau_{j}$ (Amit, 1986; Kamien and Schwartz, 1991). This is a boundary value differential equation system, that must be particularized for each specific problem. In the next sections we present some general examples and compute the numerical solutions.

\section{Numerical results}

In order to analyze the effect of upgrade-rebate strategy on a firm's profits and sales, we study a monopolistic firm which manages successive product diffusion waves. As analytical solutions of the problems are not feasible, we solve the optimal problems numerically. We introduce several cases with increasing difficulty. For all the examples considered, we compare the numerical results of upgrade-rebate implementation with the benchmark case when the firm does not carry out the strategy.

\subsection{Managing two generations}

First we study the optimal behavior of the firm which manages the diffusion of two product generations assuming that the monopolistic firm takes the prices of the products as given. Next, relaxing this assumption, we examine a firm which optimally controls for prices and analyze the effect of upgrade-rebate strategy on firm profits and product diffusion waves. Finally, we discuss the scenario, when the firm provides the second generation product absolutely for free to the upgraders.

\subsubsection{Two generations example with exogenous prices}

We first present a simple case of a monopolistic firm which manages two waves of successive product generations. We assume that prices of the product generations are given exogenously. Before the second generation is introduced, i.e. $\tau_{1}<t<\tau_{2}$, the state equation system is the following:

$$
\left\{\begin{array}{l}
\dot{f}_{11}=\left(p_{11}+q_{11} f_{11}(t)\right)\left(1-f_{11}(t)\right)\left(1-\theta_{11} P_{1}(t)\right), \\
\dot{f}_{12}=0, \dot{f}_{22}=0, \dot{r}_{12}=0 .
\end{array}\right.
$$

After the introduction of the second generation, $\tau_{2}<t<T$, the system of state equations turns to:

$$
\left\{\begin{array}{l}
\dot{f}_{11}=\left(p_{11}+q_{11} f_{11}(t)\right)\left(1-f_{11}(t)-f_{12}(t)\right)\left(1-\theta_{11} P_{1}(t)\right) \\
\dot{f}_{12}=\left(p_{12}+q_{12} f_{12}(t)+q_{22} f_{22}(t)+b_{12} r_{12}(t) f_{11}(t)\right)\left(1-f_{11}(t)-f_{12}(t)\right)\left(1-\theta_{12} P_{2}(t)\right) \\
\dot{f}_{22}=\left(p_{22}+q_{12} f_{12}(t)+q_{22} f_{22}(t)+b_{12} r_{12}(t) f_{11}(t)\right)\left(1-f_{22}(t)\right)\left(1-\theta_{22} P_{2}(t)\right) \\
\dot{r}_{12}=\left(\gamma_{12}+\beta_{12} r_{12}(t)\right)\left(1-r_{12}(t)\right) \phi_{12} D_{12}(t) .
\end{array}\right.
$$

The company profits are given by

$$
\begin{aligned}
\Pi= & \int_{0}^{\infty} e^{-r t} \Pi(t) d t=\int_{\tau_{1}}^{\tau_{2}} e^{-r t} \Pi_{1}(t) d t+\int_{\tau_{2}}^{\infty} e^{-r t} \Pi_{2}(t) d t \\
\Pi_{1}(t)= & \dot{f}_{11} m_{1}\left(P_{1}(t)-c_{1}(t)\right) \\
\Pi_{2}(t)= & \left(\Pi_{1}(t)+\left(\dot{f}_{12} m_{1}+\dot{f}_{22} m_{2}+f_{11} m_{1} \dot{r}_{12}+\dot{f}_{11} m_{1} r_{12}\right)\left(P_{2}(t)-c_{2}(t)\right)\right. \\
& \left.-\left(f_{11} m_{1} \dot{r}_{12}+\dot{f}_{11} m_{1} r_{12}\right){ }_{5} D_{12}(t)\right) .
\end{aligned}
$$


The Hamiltonian conditions are given in Appendix A1. The system cannot be solved analytically. We compute the numerical solution for the following values of the parameters. We assume arbitrary total market sizes of $m_{1}=2000$ and $m_{2}=3000$ for the first and the second generation products, respectively. We take the following values for the coefficients of innovation: $p_{11}=0.003, p_{12}=0.001$, and $p_{22}=0.003$; and coefficients of imitation: $q_{11}=0.05, q_{12}=0.05$, and $q_{22}=0.05$. To capture the effect of price, we initially set $\theta_{11}=0.002, \theta_{12}=0.002, \theta_{22}=0.002$. We assume that $b_{12}=0.07$, which is the parameter showing how the product diffusion is affected by the proportion of upgraders through the rebate program. For the upgraders diffusion equation we set the parameters of innovation and imitation as $\gamma_{12}=0.03$ and $\beta_{12}=0.3$, respectively; and for the parameter of the sensitivity to the rebate discounts as $\phi_{12}=0.0005$. We also set $P_{1}=300, P_{2}=300$, and $c_{1}=100, c_{2}=100$, i.e. the unit price and cost parameters for the first and second generation products. The discount rate is set to $r=0.05$. We assume that the second generation is introduced at $\tau_{2}=65$ and compute the solution for a large time length $(T=300)$. The results are relatively robust when we tried other parametric values in the same ranges.

We insert the optimality conditions of the rebate strategy into eight differential equations (four equations of state variables given by equations (4) and (5), and four equations of multipliers defined by (6) and (7)-(10) defined before and after the introduction time of the second generation $\tau_{2}$, respectively). We end up with a system of 8 differential equations with 8 unknowns, with 4 initial conditions, 4 boundary conditions, as well as continuity conditions of the state variables and the multipliers at $\tau_{2}$. We solve the resulting BVP numerically, using the Galerkin-Collocation method (for an introduction see, for instance, Judd 1998).

Figure 1 shows the effect of the upgrade-rebate program on the sales diffusion for this set of parameters. From Figure 1 panel (c), the net penetration of the second generation product is significantly accelerated. The upgrade-rebate program also speeds up the natural upgrading process from generation 1 to generation 2 (Figure 1 panel (b)). The implementation of the program would result into a faster and eventually higher proportion of adopters buying the second generation product, but who would have bought the older generation had the second generation product not been introduced. On the other hand, these positive effects of the program on the sales diffusion of the second generation product is partially offset by a lower proportion of adopters of the first generation product (see Figure 1 panel (a)).

Figure 1: effect of the upgrade-rebate program on the sales
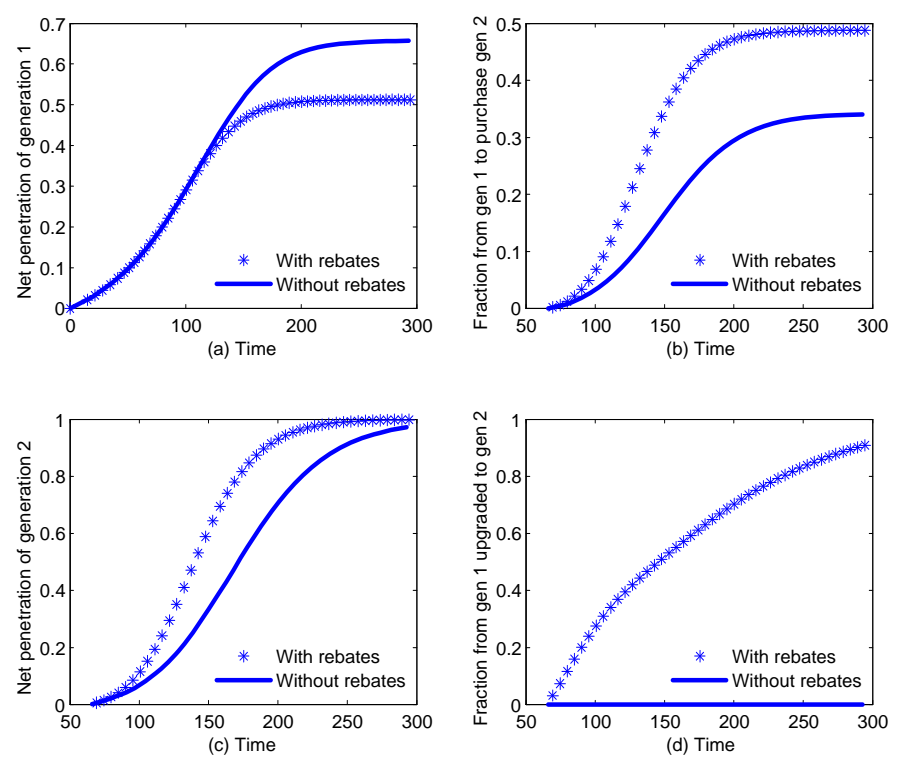

For this set of parameters, the optimal total discounted profit is $\Pi=15369$ for the benchmark case and $\Pi=16205$ if the company implements the trade-in strategy. Thus, the implementation of trade-in strategy increases the total discounted profits of the company by nearly $5.44 \%$.

Figure 2 shows the optimal rebate amounts over time. As it can be seen, the optimal rebate strategy is to start at a somewhat high level and to decrease it gradually over time. The comparison of the optimal 
rebate strategy with the price value of the second generation reveals that initially for the company it is optimal to give the buyers of the first generation monetary incentives to buy the second generation product (i.e. $D_{12}(t)>P_{2}$ up to some $t$ ).

Figure 2: Optimal rebates

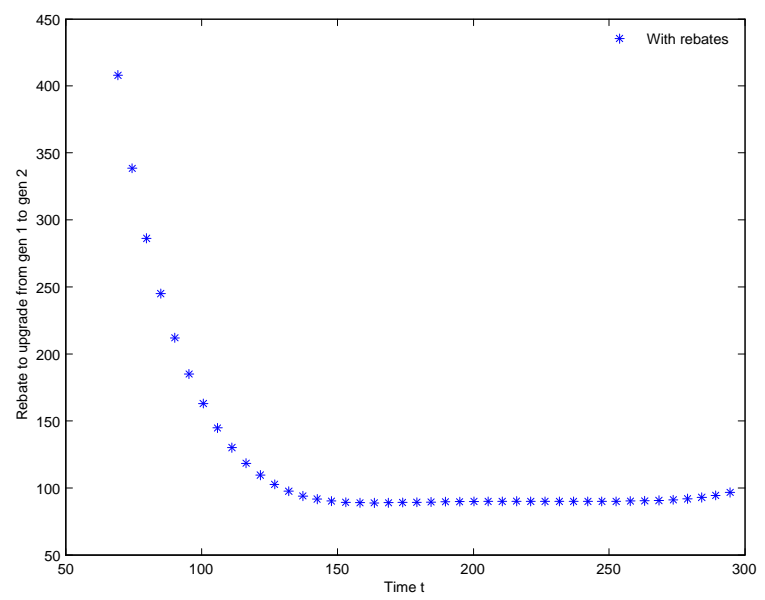

Figure 3 shows the optimal current profits (panel a) and discounted profits (panel b). Under both strategy scenarios (i.e. implementing or not upgrade-rebate policy) optimal current profits increase over time but after some time decline becoming closer to zero. However, when upgrade-rebate strategy is carried out, optimal profits peak earlier and at a higher level. Not surprisingly, discounted profits asymptotically tend to zero.

Figure 3. optimal current and discounted profits
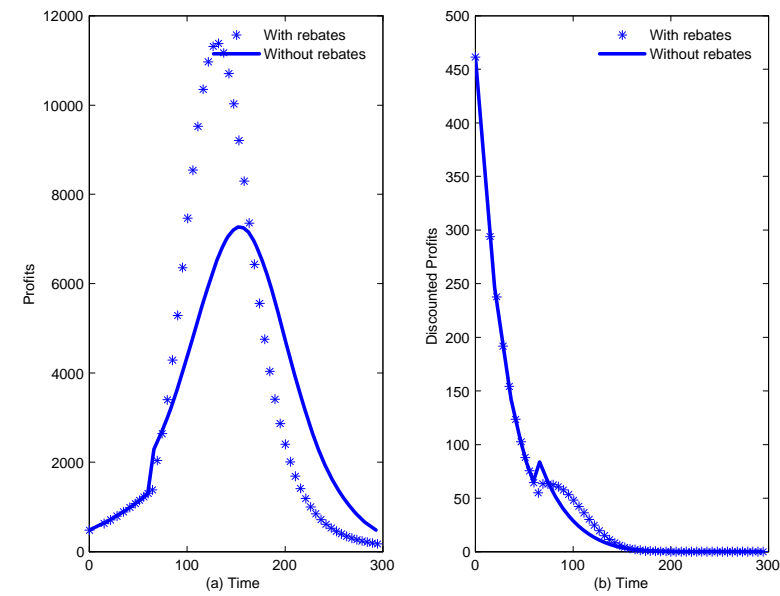

\subsubsection{Two generation example with prices as controls}

Next, we relax the assumption of exogenous prices and discuss a more realistic case of two product generations, when the firm maximizes its life-time profits optimally choosing prices and rebate amounts. We discuss the optimal conditions of the firm's maximization problem in the Appendix A2. We solved the system of differential equations using the Galerkin-Collocation method used in the previous case. 
Figure 4. Effect of the upgrade-rebate program over the optimal prices
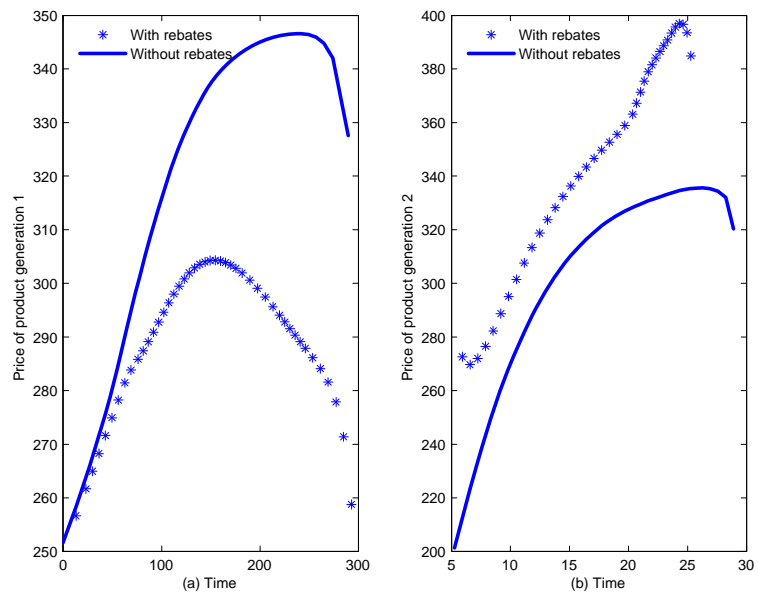

Figures 4 and 5 illustrate the effect of the upgrade-rebate program on the diffusion of the fraction of buyers and the optimal prices. Comparing visually Figure 4 with the case when the prices are given exogenously (Figure 1) we observe that the diffusion acceleration effect of the program is less prominent. However, the implementation of the program allows the company to charge higher prices for the second product generation. On the other hand, the company charges lower prices for the first product generation so that to mitigate the deceleration effect of the program on the fraction of buyers of the first generation product (see Figure 5).

Figure 5.Effect of the upgrade-rebate program over the diffusion
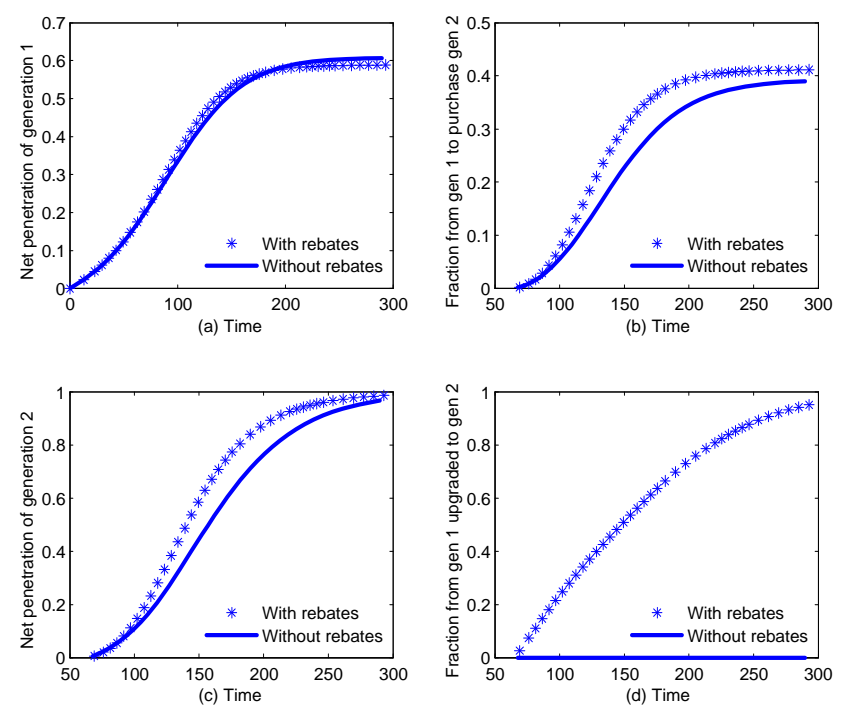

Overall, for this set of parameters the optimal total discounted profit is $\Pi=16120$ for the benchmark case and $\Pi=16820$ if the company implements the trade-in strategy. As expected, the values of optimal total discounted profits for both scenarios are higher than the corresponding values when the prices are given exogenously. The implementation of trade-in strategy increases the total discounted profits of the company by nearly $4.34 \%$. Interestingly, the percentage gain in profits is now less than that of the case when the prices are exogenously given. The intuitive explanation is that by handling prices the company has more degrees of freedom to accelerate the flows in-and-between both generations, so the effect of an additional control (e.g., rebates) is smaller. 


\subsubsection{Two generation example, when returns-upgrades are for free}

The results of the previous examples show that the upgrade-rebate program substantially increases the profits of the firm. The program accelerates the diffusion, but also increases the total number of the buyers of the second generation product. Thus, it is still questionable if the increase in profits of the firm is due to faster diffusion of the sales or merely to more buyers of the second generation product.

We explore this issue by considering a situation where the firm provides the upgraders the product of the new generation for free. Providing free upgrading is suboptimal for the firm. However, this allows us to see if the increase of profits is due to diffusion acceleration of the second generation, as the firm does not earn anything from those customers who upgrade.

The firm's optimization problem is similar to that given in the first example with exogenous prices with the exception that $D_{12}=P_{2}$. We also abstract from the pricing strategy of the firm, assuming the prices as given. Thus, the BVP for this scenario is given as in (4)-(10), substituting for $D_{12}$ by $P_{2}$.

We compute the numerical solution using the same values for the parameters. Because of space limitations, we do not provide the diffusion paths of the fraction of buyers. However, we report that the diffusion acceleration effect on the second generation product is prominent. Obviously, the optimal life-time profits are lower for this suboptimal case than in the first example, $\Pi=15371$ for the benchmark case and $\Pi=15902$ when the upgrade-rebate strategy is implemented. Thus, even though the company would not earn anything from those customers who buy the first generation product and then upgrade to the second generation, it still faces a $3.45 \%$ increase in profits which is due to acceleration effect of the program.

\subsection{Managing three generations}

We also conduct a similar analysis for the case when the company manages diffusion waves of 3 generations of a product. We provide the representation of the optimal control problem and its maximum principle conditions in the Appendix A3.

We solve numerically the system of differential equations for similar values of parameters. We set the market size of the third generation product as $m_{3}=3000$. We take the following values for the coefficients of innovation: $p_{11}=0.002, p_{12}=0.002, p_{13}=0.002, p_{22}=0.002, p_{23}=0.002, p_{33}=0.004$; and coefficients of imitation: $q_{11}=0.03, q_{12}=0.03, q_{13}=0.03, q_{22}=0.05, q_{23}=0.05, q_{33}=0.05$. All the price sensitivity parameters are set to $\theta_{i j}=0.002$. We assume that $b_{13}=0.07, b_{23}=0.07$. For the upgraders diffusion equation we set the parameters as $\gamma_{i j}=0.05, \beta_{i j}=0.1, \phi_{i j}=0.0005$. Furthermore, the unit price and cost parameters of the third generation are assumed to be equal to those of the previous generations $P_{3}=300$ and $c_{3}=100$, respectively. We assume that the second and the third generations are introduced at $\tau_{2}=90$ and $\tau_{3}=160$. The rest of the parameters of the model are assumed to be the same as in the case of the two generations examples.

For this set of parameters the optimal total discounted profit is $\Pi=8509$ for the benchmark case and $\Pi=8331$ if the company implements the trade-in strategy. The optimal discounted profits under the two scenarios are less than in the case of two generations as innovator and imitator coefficients are smaller. The percentage gain in profits is also less, mostly because the second and the third generations are introduced late (at 90th and 160th period, respectively). Still, the implementation of trade-in strategy increases the total discounted profits of the company by nearly $2.13 \%$.

Figure 6 shows the effect of the program on the diffusion of the buyers' proportions. On the one hand, the trade-in strategy slows down the diffusion of the proportion of the buyers of the first generation product (Figure 6 panel (a)). On the other hand, it speeds up the diffusion of the other proportions of the customers. However, this effect is different across the proportion of buyers of second and third generations. The second generation's diffusion is accelerated less as some fraction of customers of the second generation trade-up for the third generation, making the opposite effect on the acceleration of the second generation. The upgrade-rebate program mostly affects the proportions of buyers of the third generation $\left(f_{13}, f_{23}, f_{33}\right)$. 
Figure 6. Effect of the program on the diffusion
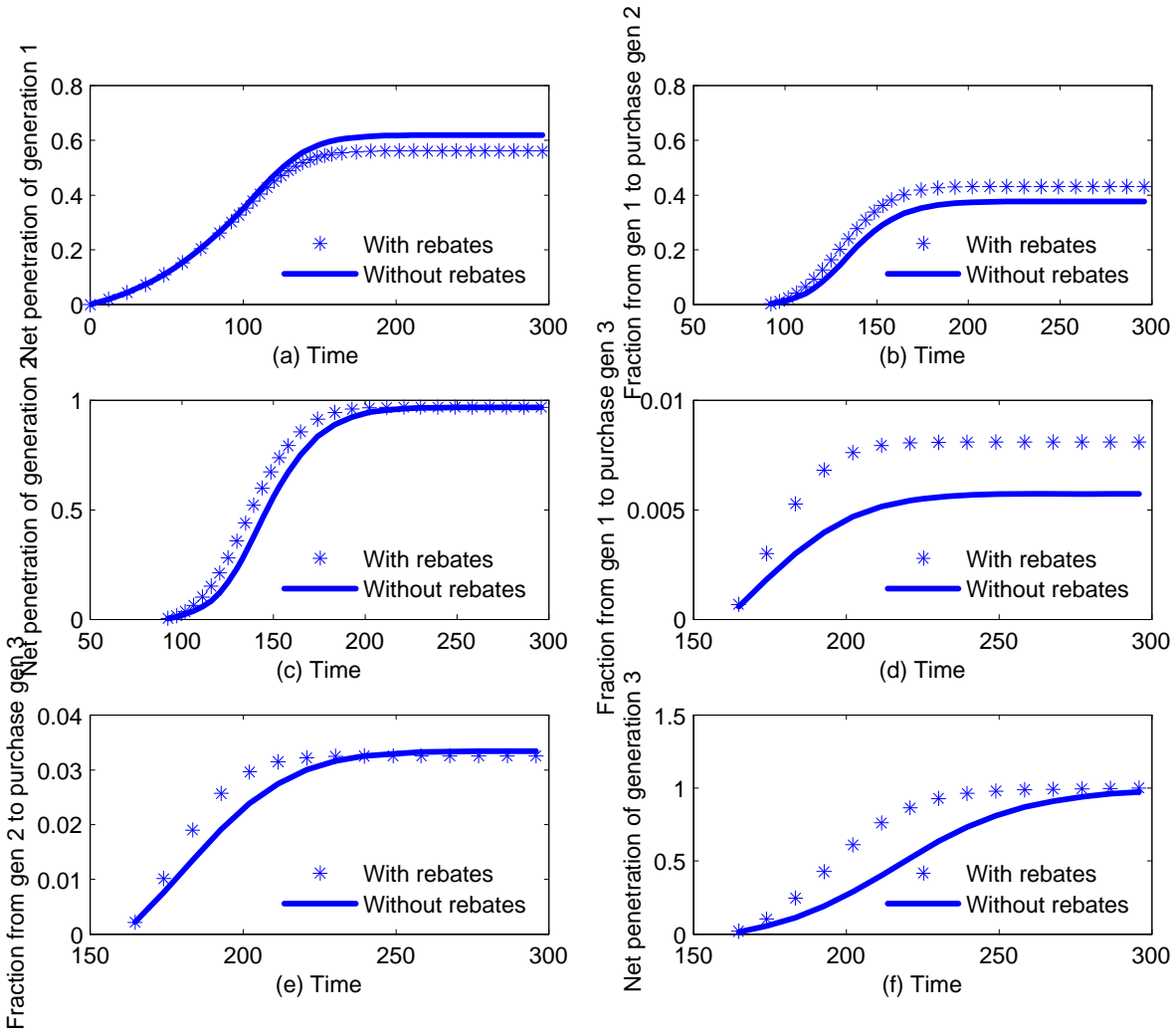

\section{Conclusion}

This paper studies how to use upgrade-rebate program as a strategic tool in order to manage the diffusion of successive product generations. Prior literature has considered upgrade-rebate program as a means to disable second hand market of the products, to decrease the regret of customers of buying the old generation product, to price discriminate the customers. However, most of the previous models analyze the program in an essentially static context. This paper takes a different approach to analyze the upgrade-rebate program in a dynamic context, where it is used to control the whole diffusion of the successive generations.

We first build a general diffusion model for successive product generations. Our model allows for leapfroggers, and can be easily adopted to analyze the upgraders through the upgrade-rebate program. The model can be applied to study the diffusion of non-durables, as well as durable products.

In order to analyze the effect of upgrade-rebate strategy, we particularize the general model for some general examples and numerically solve them for certain sets of parameter values. For all the examples, we demonstrate that the trade-in program accelerates the diffusion of the later generations but has the reverse effect for the diffusion of the old generation product. In order to quantify the effect of the program, we compute the optimal discounted profits under scenarios of implementing upgrade-rebate strategy or not. We find that the implementation of the upgrade-rebate strategy provides a $2-5 \%$ increase in total discounted profits.

The size of the percentage gain in profits varies depending on several conditions. For two generations, we demonstrate that when the firm takes the product prices as given, the gain in profits is the highest, more than $5 \%$. However, when the firm also controls for prices, the increase in profits is less: $4.34 \%$. We show that under trade-in strategy the firm changes its pricing policy, charging lower levels of prices of the first and higher levels for the second generation products.

We also find that for the firm it is optimal to provide the upgraders rebate amounts even higher than the price of the new generation up to some time. Subsidizing adopters and product giveaways have been studied previously in the context of one product generation (e.g. Kalish and Lilien 1983, Lehmann and Esteban-Bravo 
2006). Kalish and Lilien (1983) demonstrate that mostly optimal subsidies are likely to decline over time. Lehmann and Esteban-Bravo (2006) examine when it is optimal to give away some products to innovators in a market consisting of two segments. In the context of two product generations, we show that even if the firm provides the upgraders the new generation products for free, it still faces more than a $3 \%$ increase in profits. We argue that this gain in profits is not due to more adopters of the new generation product nor to the change in pricing strategy of the firm, but merely to the diffusion acceleration effect of the upgrade-rebate strategy.

Most managers favor faster waves of their product generations. We show that a manager could create a tsunami through a trade-in strategy accelerating the diffusion of later generations. Obviously, this strategy should be carried out in parallel with other marketing mix decisions, such as pricing. A simpler implication is that a manager could provide new generation products to the owners of the old generation, even for free, in order to achieve rapid adoption of the new generation.

Our modeling framework has made a number of assumptions that can be relaxed to have a better understanding of trade-in strategy in a dynamic context. For example, we assumed that the proportion of customers who upgrade once never upgrade again in the future, i.e. rebate-upgrades are not iterated. We can relax this assumption, albeit increasing complexity. For instance, we can allow a maximum of $J$ iterated rebate-upgrades, then sales for all generations are given by the vector

$$
\begin{aligned}
S(t) & =\dot{\mathbf{f}}(t)^{\prime} m+\sum_{j=1}^{J} \frac{d}{d t}\left\{\mathbf{r}(t)^{j} \mathbf{f}(t)^{\prime} m\right\} \\
\frac{d}{d t}\left\{\mathbf{r}(t)^{j} \mathbf{f}(t)^{\prime} m\right\} & =\left(j \mathbf{f}(s) \dot{\mathbf{r}}(s)^{j-1}+\mathbf{f}(s) \mathbf{r}(s)^{j}\right)^{\prime} m
\end{aligned}
$$

where $\frac{d}{d t}\left\{\mathbf{r}(t)^{j} \mathbf{f}(t)^{\prime} m\right\}$ are sales associated to $j-t h$ iterated upgrade, and the last equality is based on

$$
\left(\mathbf{f}(t) \mathbf{r}(t)^{j}\right)^{\prime} m=\int_{0}^{t}\left(j \mathbf{f}(s) \dot{\mathbf{r}}(s)^{j-1}+\dot{\mathbf{f}}(s) \mathbf{r}(s)^{j}\right)^{\prime} m d s
$$

since $j \int_{0}^{t}\left(\mathbf{f}(s) \dot{\mathbf{r}}(s)^{j-1}\right)^{\prime} m d s=\left(\mathbf{f}(t) \mathbf{r}(t)^{j}\right)^{\prime} m-\int_{0}^{t}\left(\dot{\mathbf{f}}(s) \mathbf{r}(s)^{j}\right)^{\prime} m d s$. But we have not dealt with this case in the paper, i.e. we set $J=1$.

Additional refinement could be considering other marketing mix variables such as advertising, and the timing decision of product generation launch and trade-in strategies. Neither do we consider competition for the firm from the second-hand markets. We leave these extensions for future research.

\section{References}

Ann van Ackere, Diane J. Reyniers (1995) Trade-ins and Introductory Offers in a Monopoly. The RAND Journal of Economics, 26: 58-74.

Амiт, R. (1986). Petroleum reservoir exploitation: Switching from primary to secondary recovery. Operations Research 34: 534-549.

Cohen, Morris A., Jehoshua Eliashberg, Teck-Hua Ho (1996) New Product Development: The Performance and Time-to-Market Tradeoff. Management Science, 42: 173-186.

Desai, P., O. Koenigsberg, D. Purohit (2007) Research Note: The Role of Production Lead Time and Demand Uncertainty in Durable Goods Markets. Management Science 53: 150-158.

Dhebar, Anirudh (1996) Speeding High-Tech Producer, Meet the Balking Consumer. Sloan Management Review 36: 37-49.

Dockner, E., S. Jorgensen (1988) Optimal pricing strategies for new products in dynamic oligopolies. Marketing Science 7: 315-334.

Fudenberg, Drew, Jean Tirole (1998) Upgrades, Tradeins, and Buybacks. RAND Journal of Economics 29: 235-258. 
Hans S. Heese, Kyle Cattani, Geraldo Ferrer, Wendell Gilland, Aleda V. Roth (2005) Competitive advantage through take-back of used products. European Journal of Operational Research, 164: $143-157$.

Horsky, D., K. Mate (1988) Dynamic advertising strategies of competing durable good producers. Marketing Science 7: 356-367.

JuDD, K. (1998) Numerical methods in economics. The MIT press.

Lee, In Ho, Jonghwa Lee (1998) A Theory of Economic Obsolescence Journal of Industrial Economics 46: 383-401.

Lehmann, Donald, Mercedes Esteban-Bravo (2006) When giving some away makes sense to jumpstart the diffusion process. Marketing Letters 17: 243-254.

Mahajan, V., E. Muller (1996) Timing, diffusion, and substitution of successive generations of technological innovations: The IBM mainframe case. Technological Forecasting and Social Change 51: 109-132.

Kalish, Shlomo, Gary L. Lilien (1983) Optimal price subsidy policy for accelerating the diffusion of innovation. Marketing Science 2: 407-420.

Kamien, M., N. Schwartz (1991) Dynamic Optimization: The Calculus of Variations and Optimal Control in Economics and Management. North Holland, New York.

Koenigsberg, Oded, Preyas Desai, Devavrat Purohit (2007) The Role of Production Lead Time and Demand Uncertainty in Marketing Durable Goods. Management Science 53: 150-58.

Koenigsberg, Oded, Mark Ferguson (2007) How Should a Firm Manage Deteriorating Inventory? Production and Operations Management 16: 306-21.

Kornish , Laura J. (2001) Pricing for a Durable-Goods Monopolist under Rapid Sequential Innovation. Management Science 47: 1552-1561.

Norton, J., F. BAss (1987) A diffusion theory model of adoption and substitution for successive generations of high-technology products. Management Science 33: 1069-1086.

Norton, J., F. BAss (1987) Evolution of technological change: The law of capture. Sloan Management Review 33: 66-77.

Putsis, William P. (1993) Why Put Off Until Tomorrow What You Can Do Today: Incentives and the Timing of New Product Introduction. Journal of Product Innovation Management 10: 195-203.

Ray, Saibal, T. Boyaci, N. Aras (2005) Optimal Prices and Trade-in Rebates for Durable, Remanufacturable Products. Manufacturing $\mathcal{E}$ Service Operations Management 7: 208-228.

Stremersch, S., E. Muller, R. Peres (2010) Does new product growth accelerate across technology generations? Marketing Letters 21: 103-120.

Venkatesh, Viswanath, Susan A. Brown (2001) A Longitudinal Investigation of Personal Computers in Homes: Adoption Determinants and Emerging Challenges. MIS Quarterly 25: 71-102. 


\section{Appendix}

\subsection{A1: Two generations with exogenous prices}

Let $\lambda=\left(\lambda_{1}(t), \lambda_{2}(t), \lambda_{3}(t)\right)$ be the multiplier vector associated with the state variables $f_{11}, f_{12}, f_{22}$, respectively, and $\mu$ be the multiplier associated with $r_{12}$. Also, let the Hamiltonian function $H$ of the optimal control be given by:

$$
H= \begin{cases}H_{1} & \text { if } \tau_{1}<t<\tau_{2} \\ H_{2} & \tau_{2}<t<\infty\end{cases}
$$

where

$$
H_{1}\left(f_{t}, r_{t}, D_{t}, \lambda_{t}, \mu_{t}\right)=e^{-r t} \Pi_{1}(t)+\lambda_{1} \dot{f}_{11}
$$

and

$$
H_{2}\left(f_{t}, r_{t}, D_{t}, \lambda_{t}, \mu_{t}\right)=e^{-r t} \Pi_{2}(t)+\lambda_{1} \dot{f}_{11}+\lambda_{2} \dot{f}_{12}+\lambda_{3} \dot{f}_{22}+\mu_{1} \dot{r}_{12}
$$

where $\lambda_{t}$ and $\mu_{t}$ be the multiplier matrixes associated with the state variables $f_{t}$ and $r_{t}$, respectively. The maximum principle conditions are

$$
\begin{aligned}
\frac{\partial H_{t}}{\partial D_{12}} & =0, \\
\dot{\lambda}_{t} & =-\frac{\partial H_{t}}{\partial f_{t}}, \\
\dot{\mu}_{t} & =-\frac{\partial H_{t}}{\partial r_{t}}
\end{aligned}
$$

together with initial conditions at introduction times, and transversality conditions of $\lambda_{t}$ and $\mu_{t}$ tending to zero (numerically we equalize them to zero for large $t$ ). Also, we require the state variables and multipliers be continuous at $\tau_{2}$.

Maximum Principle conditions for $\tau_{1}<t<\tau_{2}$

As the second generation is not introduced by time $\tau_{2}$, there is no optimality condition for the rebates. The multiplier is obtained from the following differential equation:

$$
\begin{aligned}
& \dot{\lambda}_{1}=-e^{-r t}\left(q_{11}\left(1-f_{11}(t)\right)-p_{11}-q_{11} f_{11}(t)\right)\left(1-\theta_{11} P_{1}(t)\right)\left(m_{1}\left(P_{1}(t)-c_{1}(t)\right)+\lambda_{1} e^{r t}\right) \\
& \dot{\lambda}_{2}=0, \dot{\lambda}_{3}=0, \dot{\mu}_{1}=0
\end{aligned}
$$

Maximum Principle conditions $\tau_{2}<t<T$

The optimality conditions for rebate $D_{12}$ yield:

$$
\begin{gathered}
0=e^{-r t} f_{11} m_{1}\left(\gamma_{12}+\beta_{12} r_{12}(t)\right)\left(1-r_{12}(t)\right) \phi_{12}\left(\left(P_{2}(t)-c_{2}(t)\right)-2 D_{12}(t)+\frac{\mu_{1} e^{r t}}{f_{11} m_{1}}\right) \\
-e^{-r t}\left(p_{11}+q_{11} f_{11}(t)\right)\left(1-f_{11}(t)-f_{12}(t)\right)\left(1-\theta_{11} P_{1}(t)\right) m_{1} r_{12} \\
D_{12}(t)=\frac{1}{2}\left(\left(P_{2}(t)-c_{2}(t)\right)+\frac{\mu_{1} e^{r t}}{f_{11} m_{1}}\right) \\
-\frac{\left(p_{11}+q_{11} f_{11}(t)\right)\left(1-f_{11}(t)-f_{12}(t)\right)\left(1-\theta_{11} P_{1}(t)\right) r_{12}}{2 f_{11}\left(\gamma_{12}+\beta_{12} r_{12}(t)\right)\left(1-r_{12}(t)\right) \phi_{12}}
\end{gathered}
$$


The state variables and multipliers are obtained from the Boundary Value Problem, consisted of the four differential equations of the state variables and 4 differential equations of multipliers given by:

$$
\begin{aligned}
\dot{\lambda}_{1}= & -e^{-r t}\left(q_{11}\left(1-f_{11}(t)-f_{12}(t)\right)-p_{11}-q_{11} f_{11}(t)\right)\left(1-\theta_{11} P_{1}(t)\right) \times \\
& \left(m_{1}\left(P_{1}(t)-c_{1}(t)+r_{12}\left(P_{2}(t)-c_{2}(t)-D_{12}(t)\right)\right)+\lambda_{1} e^{r t}\right) \\
& -e^{-r t}\left(b_{12} r_{12}(t)\left(1-f_{11}(t)-f_{12}(t)\right)-\left(p_{12}+q_{12} f_{12}(t)+q_{22} f_{22}(t)+b_{12} r_{12}(t) f_{11}(t)\right)\right) \times \\
& \left(1-\theta_{12} P_{2}(t)\right)\left(m_{1}\left(P_{2}(t)-c_{2}(t)\right)+\lambda_{2} e^{r t}\right) \\
& -e^{-r t} b_{12} r_{12}(t)\left(1-f_{22}(t)\right)\left(1-\theta_{22} P_{2}(t)\right)\left(m_{2}\left(P_{2}(t)-c_{2}(t)\right)+\lambda_{3} e^{r t}\right) \\
& -e^{-r t} m_{1}\left(\gamma_{12}+\beta_{12} r_{12}(t)\right)\left(1-r_{12}(t)\right) \phi_{12} D_{12}(t)\left(P_{2}(t)-c_{2}(t)-D_{12}(t)\right)
\end{aligned}
$$

$$
\begin{aligned}
\dot{\lambda}_{2}= & e^{-r t}\left(p_{11}+q_{11} f_{11}(t)\right)\left(1-\theta_{11} P_{1}(t)\right) \times \\
& \left(m_{1}\left(P_{1}(t)-c_{1}(t)+r_{12}\left(P_{2}(t)-c_{2}(t)-D_{12}(t)\right)\right)+\lambda_{1} e^{r t}\right) \\
& -e^{-r t}\left(q_{12}\left(1-f_{11}(t)-f_{12}(t)\right)-\left(p_{12}+q_{12} f_{12}(t)+q_{22} f_{22}(t)+b_{12} r_{12}(t) f_{11}(t)\right)\right) \times \\
& \left(1-\theta_{12} P_{2}(t)\right)\left(m_{1}\left(P_{2}(t)-c_{2}(t)\right)+\lambda_{2} e^{r t}\right) \\
& -e^{-r t} q_{12}\left(1-f_{22}(t)\right)\left(1-\theta_{22} P_{2}(t)\right)\left(m_{2}\left(P_{2}(t)-c_{2}(t)\right)+\lambda_{3} e^{r t}\right)
\end{aligned}
$$

$$
\begin{aligned}
\dot{\lambda}_{3}= & 0 \\
& -e^{-r t} q_{22}\left(1-f_{11}(t)-f_{12}(t)\right)\left(1-\theta_{12} P_{2}(t)\right)\left(m_{1}\left(P_{2}(t)-c_{2}(t)\right)+\lambda_{2} e^{r t}\right)
\end{aligned}
$$$$
-e^{-r t}\left(q_{22}\left(1-f_{22}(t)\right)-\left(p_{22}+q_{12} f_{12}(t)+q_{22} f_{22}(t)+b_{12} r_{12}(t) f_{11}(t)\right)\right) \times
$$$$
\left(1-\theta_{22} P_{2}(t)\right)\left(m_{2}\left(P_{2}(t)-c_{2}(t)\right)+\lambda_{3} e^{r t}\right)
$$

$$
\begin{aligned}
\dot{\mu}_{1}= & -e^{-r t}\left(\beta_{12}\left(1-r_{12}(t)\right)-\left(\gamma_{12}+\beta_{12} r_{12}(t)\right)\right) \phi_{12} D_{12}(t) \times \\
& \left(f_{11} m_{1}\left(P_{2}(t)-c_{2}(t)-D_{12}(t)\right)+\mu_{1} e^{r t}\right) \\
& -e^{-r t}\left(p_{11}+q_{11} f_{11}(t)\right)\left(1-f_{11}(t)-f_{12}(t)\right)\left(1-\theta_{11} P_{1}(t)\right) m_{1}\left(P_{2}(t)-c_{2}(t)-D_{12}(t)\right) \\
& -e^{-r t} b_{12} f_{11}(t)\left(1-f_{11}(t)-f_{12}(t)\right)\left(1-\theta_{12} P_{2}(t)\right)\left(m_{1}\left(P_{2}(t)-c_{2}(t)\right)+\lambda_{2} e^{r t}\right) \\
& -e^{-r t} b_{12} f_{11}(t)\left(1-f_{22}(t)\right)\left(1-\theta_{22} P_{2}(t)\right)\left(m_{2}\left(P_{2}(t)-c_{2}(t)\right)+\lambda_{3} e^{r t}\right)
\end{aligned}
$$

For the benchmark scenario when the upgrade-rebate program is not implemented, the optimal control problem is a special case where

$$
D_{12}(t)=0, \dot{r}_{12}=0, \dot{\mu}_{1}=0
$$

\subsection{A.2. Two generations with endogenous prices}

The optimal solution of this scenario is similar to that of the case when the firm takes the prices as given. The maximum principle conditions are 


$$
\begin{aligned}
\frac{\partial H_{t}}{\partial D_{12}} & =0, \\
\frac{\partial H_{t}}{\partial P_{1}} & =0, \\
\frac{\partial H_{t}}{\partial P_{2}} & =0, \\
\dot{\lambda}_{t} & =-\frac{\partial H_{t}}{\partial f_{t}}, \\
\dot{\mu}_{t} & =-\frac{\partial H_{t}}{\partial r_{t}}
\end{aligned}
$$

together with initial conditions at introduction times, and transversality conditions $\lambda_{t}$ and $\mu_{t}$ tending to zero.

Maximum Principle conditions $\tau_{1}<t<\tau_{2}$

The optimality condition for price is:

$$
0=-e^{-r t}\left(p_{11}+q_{11} f_{11}(t)\right)\left(1-f_{11}(t)\right) \theta_{11} m_{1}\left(P_{1}(t)-c_{1}(t)-\frac{\left(1-\theta_{11} P_{1}(t)\right)}{\theta_{11}}+\frac{\lambda_{1}}{e^{-r t} m_{1}}\right)
$$

We rearrange the terms to get:

$$
P_{1}(t)=\frac{1}{2}\left(c_{1}(t)+\frac{1}{\theta_{11}}-\frac{\lambda_{1}}{e^{-r t} m_{1}}\right)
$$

As the second generation is not introduced before $\tau_{2}$, there is no optimality condition for rebate and price of the second generation. The multiplier is given from the differential equation as in (6).

Maximum Principle conditions $\tau_{2}<t<T$

The optimality conditions for discount $D_{12}$ yield:

$$
\begin{aligned}
0= & e^{-r t} f_{11} m_{1}\left(\gamma_{12}+\beta_{12} r_{12}(t)\right)\left(1-r_{12}(t)\right) \phi_{12}\left(\left(P_{2}(t)-c_{2}(t)\right)-2 D_{12}(t)+\frac{\mu_{1} e^{r t}}{f_{11} m_{1}}\right) \\
& -e^{-r t}\left(p_{11}+q_{11} f_{11}(t)\right)\left(1-f_{11}(t)-f_{12}(t)\right)\left(1-\theta_{11} P_{1}(t)\right) m_{1} r_{12}
\end{aligned}
$$

The optimality conditions for prices are:

$$
\begin{aligned}
0= & -e^{-r t}\left(p_{11}+q_{11} f_{11}(t)\right)\left(1-f_{11}(t)-f_{12}(t)\right) \theta_{11} m_{1} \times \\
& \left(P_{1}(t)-c_{1}(t)+r_{12}\left(P_{2}(t)-c_{2}(t)\right)-\frac{\left(1-\theta_{11} P_{1}(t)\right)}{\theta_{11}}-r_{12} D_{12}(t)+\frac{\lambda_{1}}{e^{-r t} m_{1}}\right) \\
0= & -e^{-r t}\left(p_{12}+q_{12} f_{12}(t)+q_{22} f_{22}(t)+b_{12} r_{12}(t) f_{11}(t)\right)\left(1-f_{11}(t)-f_{12}(t)\right) \theta_{12} m_{1} \times \\
& \left(P_{2}(t)-c_{2}(t)-\frac{\left(1-\theta_{12} P_{2}(t)\right)}{\theta_{12}}+\frac{\lambda_{2}}{e^{-r t} m_{1}}\right)- \\
& -e^{-r t}\left(p_{22}+q_{12} f_{12}(t)+q_{22} f_{22}(t)+b_{12} r_{12}(t) f_{11}(t)\right)\left(1-f_{22}(t)\right) \theta_{22} m_{2} \times \\
& \left(P_{2}(t)-c_{2}(t)-\frac{\left(1-\theta_{22} P_{2}(t)\right)}{\theta_{22}}+\frac{\lambda_{3}}{e^{-r t} m_{2}}\right) \\
& e^{-r t} f_{11} m_{1}\left(\gamma_{12}+\beta_{12} r_{12}(t)\right)\left(1-r_{12}(t)\right) \phi_{12} D_{12}(t) \\
& e^{-r t}\left(p_{11}+q_{11} f_{11}(t)\right)\left(1-f_{11}(t)-f_{12}(t)\right)\left(1-\theta_{11} P_{1}(t)\right) m_{1} r_{12} .
\end{aligned}
$$

We simplify the equations and represent the system as above, given three equations in matrix form as: 
$\Gamma\left(P_{1}(t), P_{2}(t), D_{12}(t)\right)^{\prime}=\Psi$, where

$$
\begin{aligned}
\Gamma_{11}= & \left(p_{11}+q_{11} f_{11}(t)\right)\left(1-f_{11}(t)-f_{12}(t)\right) \theta_{11} r_{12} \\
\Gamma_{12}= & f_{11}\left(\gamma_{12}+\beta_{12} r_{12}(t)\right)\left(1-r_{12}(t)\right) \phi_{12} \\
\Gamma_{13}= & -2 f_{11}\left(\gamma_{12}+\beta_{12} r_{12}(t)\right)\left(1-r_{12}(t)\right) \phi_{12} \\
\Psi_{1}= & -\left[f_{11}\left(\gamma_{12}+\beta_{12} r_{12}(t)\right)\left(1-r_{12}(t)\right) \phi_{12}\left(-c_{2}(t)+\frac{\mu_{1} e^{r t}}{f_{11} m_{1}}\right)\right. \\
& \left.-\left(p_{11}+q_{11} f_{11}(t)\right)\left(1-f_{11}(t)-f_{12}(t)\right) r_{12}\right] \\
\Gamma_{21}= & 2 \\
\Gamma_{22}=r_{12} & \Gamma_{23}=-r_{12} \\
\Psi_{2}=-\left[-c_{1}(t)-r_{12} c_{2}(t)-\frac{1}{\theta_{11}}+\frac{\lambda_{1}}{e^{-r t} m_{1}}\right] & \\
\Gamma_{31}= & -\left(p_{11}+q_{11} f_{11}(t)\right)\left(1-f_{11}(t)-f_{12}(t)\right) \theta_{11} m_{1} r_{12} \\
\Gamma_{32}= & -2\left(p_{12}+q_{12} f_{12}(t)+q_{22} f_{22}(t)+b_{12} r_{12}(t) f_{11}(t)\right)\left(1-f_{11}(t)-f_{12}(t)\right) \theta_{12} m_{1} \\
& -2\left(p_{22}+q_{12} f_{12}(t)+q_{22} f_{22}(t)+b_{12} r_{12}(t) f_{11}(t)\right)\left(1-f_{22}(t)\right) \theta_{22} m_{2} \\
\Gamma_{33}= & f_{11} m_{1}\left(\gamma_{12}+\beta_{12} r_{12}(t)\right)\left(1-r_{12}(t)\right) \phi_{12} \\
\Psi_{3}= & {\left[\left(p_{12}+q_{12} f_{12}(t)+q_{22} f_{22}(t)+b_{12} r_{12}(t) f_{11}(t)\right)\left(1-f_{11}(t)-f_{12}(t)\right) \times\right.} \\
& \theta_{12} m_{1}\left(-c_{2}(t)-\frac{1}{\theta_{12}}+\frac{\lambda_{2}}{e^{-r t} m_{1}}\right)+ \\
& \left(p_{22}+q_{12} f_{12}(t)+q_{22} f_{22}(t)+b_{12} r_{12}(t) f_{11}(t)\right)\left(1-f_{22}(t)\right) \times \\
& \theta_{22} m_{2}\left(-c_{2}(t)-\frac{1}{\theta_{22}}+\frac{\lambda_{3}}{e^{-r t} m_{2}}\right)- \\
& \left.\left(p_{11}+q_{11} f_{11}(t)\right)\left(1-f_{11}(t)-f_{12}(t)\right) m_{1} r_{12}\right]
\end{aligned}
$$

Using Cramer's rule we express $P_{1}(t), P_{2}(t), D_{12}(t)$ in terms of the state variables and multipliers. Finally,

the optimal state variables and multipliers are obtained solving the Boundary Value Problem analogously to the model with exogenous prices.

For the benchmark scenario when the upgrade-rebate program is not implemented, the optimal control problem is a special case where

$$
\dot{r}_{12}=0, D_{12}=0, \dot{\mu}_{1}=0
$$

\subsection{A.3. Three generations}

We provide the solution for the case of 3 generations only for when the 3rd generation is introduced (i.e. $t>\tau_{3}$ ). The optimality conditions before the introduction of the 3rd generation are similar to the case of two generations. 
For the case of 3 generations, the half-vectorization of $\mathbf{f}(t)$ and $\dot{\mathbf{r}}(t)$ matrices is the following:

$$
\left\{\begin{aligned}
f_{11}= & \left(p_{11}+q_{11} f_{11}(t)\right)\left(1-f_{11}(t)-f_{12}(t)-f_{13}(t)\right)\left(1-\theta_{11} P_{1}(t)\right) \\
f_{12}= & \left(p_{12}+q_{12} f_{12}(t)+q_{22} f_{22}(t)+b_{12} r_{12}(t) f_{11}(t)\right)\left(1-f_{11}(t)-f_{12}(t)-f_{13}(t)\right)\left(1-\theta_{12} P_{2}(t)\right) \\
f_{13}= & \left(p_{13}+q_{13} f_{13}(t)+q_{23} f_{23}(t)+q_{33} f_{33}(t)+b_{13} r_{13}(t) f_{11}(t)+b_{23} r_{23}(t)\left(f_{12}(t)+f_{22}(t)\right)\right) \times \\
& \left(1-f_{11}(t)-f_{12}(t)-f_{13}(t)\right)\left(1-\theta_{13} P_{3}(t)\right) \\
f_{22}= & \left(p_{22}+q_{12} f_{12}(t)+q_{22} f_{22}(t)+b_{12} r_{12}(t) f_{11}(t)\right)\left(1-f_{22}(t)-f_{23}(t)\right)\left(1-\theta_{22} P_{2}(t)\right) \\
\dot{f}_{23}= & \left(p_{23}+q_{13} f_{13}(t)+q_{23} f_{23}(t)+q_{33} f_{33}(t)+b_{13} r_{13}(t) f_{11}(t)+b_{23} r_{23}(t)\left(f_{12}(t)+f_{22}(t)\right)\right) \times \\
& \left(1-f_{22}(t)-f_{23}(t)\right)\left(1-\theta_{23} P_{3}(t)\right) \\
f_{33}= & \left(p_{33}+q_{13} f_{13}(t)+q_{23} f_{23}(t)+q_{33} f_{33}(t)+b_{13} r_{13}(t) f_{11}(t)+b_{23} r_{23}(t)\left(f_{12}(t)+f_{22}(t)\right)\right) \times \\
& \left(1-f_{33}(t)\right)\left(1-\theta_{33} P_{3}(t)\right)
\end{aligned}\right.
$$

and

$$
\left\{\begin{array}{l}
\dot{r}_{12}=\left(\gamma_{12}+\beta_{12} r_{12}(t)\right)\left(1-r_{12}(t)-r_{13}(t)\right) \phi_{12} D_{12}(t), \\
\dot{r}_{13}=\left(\gamma_{13}+\beta_{13} r_{13}(t)+\beta_{23} r_{23}(t)\right)\left(1-r_{12}(t)-r_{13}(t)\right) \phi_{13} D_{13}(t), \\
\dot{r}_{23}=\left(\gamma_{23}+\beta_{13} r_{13}(t)+\beta_{23} r_{23}(t)\right)\left(1-r_{23}(t)\right) \phi_{23} D_{23}(t)
\end{array}\right.
$$

The company profits are:

$$
\begin{aligned}
\Pi= & \int_{0}^{\infty} e^{-r t} \Pi(t) d t=\int_{0}^{\infty} e^{-r t}\left(\dot{f}_{11} m_{1}\left(P_{1}(t)-c_{1}(t)\right)\right. \\
& +\left(\dot{f}_{12} m_{1}+\dot{f}_{22} m_{2}+f_{11} m_{1} \dot{r}_{12}+\dot{f}_{11} m_{1} r_{12}\right)\left(P_{2}(t)-c_{2}(t)\right) \\
& +\left(\dot{f}_{13} m_{1}+\dot{f}_{23} m_{2}+\dot{f}_{33} m_{3}+f_{11} m_{1} \dot{r}_{13}+\dot{f}_{11} m_{1} r_{13}\right. \\
& \left.+\left(f_{12} m_{1}+f_{22} m_{2}\right) \dot{r}_{23}+\left(\dot{f}_{12} m_{1}+\dot{f}_{22} m_{2}\right) r_{23}\right)\left(P_{3}(t)-c_{3}(t)\right) \\
& -\left(f_{11} m_{1} \dot{r}_{12}+\dot{f}_{11} m_{1} r_{12}\right) D_{12}(t)-\left(f_{11} m_{1} \dot{r}_{13}+\dot{f}_{11} m_{1} r_{13}\right) D_{13}(t) \\
& \left.-\left(\left(f_{12} m_{1}+f_{22} m_{2}\right) \dot{r}_{23}+\left(\dot{f}_{12} m_{1}+\dot{f}_{22} m_{2}\right) r_{23}\right) D_{23}(t)\right) d t
\end{aligned}
$$

Let the Hamiltonian function $H$ of the optimal control be given by:

$$
\begin{aligned}
H_{t}\left(f_{t}, r_{t}, P_{t}, D_{t}, \lambda_{t}, \mu_{t}\right)= & e^{-r t} \Pi(t)+\lambda_{1} \dot{f}_{11}+\lambda_{2} \dot{f}_{12}+\lambda_{3} \dot{f}_{13}+\lambda_{4} \dot{f}_{22}+\lambda_{5} \dot{f}_{23}+\lambda_{6} \dot{f}_{33} \\
& +\mu_{1} \dot{r}_{12}+\mu_{2} \dot{r}_{13}+\mu_{3} \dot{r}_{23}
\end{aligned}
$$

where $\lambda_{t}$ and $\mu_{t}$ be the multiplier matrices associated with the state variables $f_{t}$ and $r_{t}$, respectively. The maximum principle conditions are

$$
\begin{aligned}
& \frac{\partial H_{t}}{\partial D_{12}}=0, \frac{\partial H_{t}}{\partial D_{13}}=0, \frac{\partial H_{t}}{\partial D_{23}}=0 \\
& \dot{\lambda}_{t}=-\frac{\partial H_{t}}{\partial f_{t}} \\
& \dot{\mu}_{t}=-\frac{\partial H_{t}}{\partial r_{t}} \\
& 17
\end{aligned}
$$


The optimality conditions for discounts $D_{12}, D_{13}, D_{23}$ yield, respectively:

$$
\begin{aligned}
& 0=e^{-r t} f_{11} m_{1}\left(\gamma_{12}+\beta_{12} r_{12}(t)\right)\left(1-r_{12}(t)-r_{13}(t)\right) \phi_{12}\left(\left(P_{2}(t)-c_{2}(t)\right)-2 D_{12}(t)+\frac{\mu_{1} e^{r t}}{f_{11} m_{1}}\right) \\
& -e^{-r t}\left(p_{11}+q_{11} f_{11}(t)\right)\left(1-f_{11}(t)-f_{12}(t)-f_{13}(t)\right)\left(1-\theta_{11} P_{1}(t)\right) m_{1} r_{12} \\
& D_{12}(t)=\frac{1}{2}\left(\left(P_{2}(t)-c_{2}(t)\right)+\frac{\mu_{1} e^{r t}}{f_{11} m_{1}}\right) \\
& -\frac{\left(p_{11}+q_{11} f_{11}(t)\right)\left(1-f_{11}(t)-f_{12}(t)-f_{13}(t)\right)\left(1-\theta_{11} P_{1}(t)\right) r_{12}}{2 f_{11}\left(\gamma_{12}+\beta_{12} r_{12}(t)\right)\left(1-r_{12}(t)-r_{13}(t)\right) \phi_{12}} \\
& 0=e^{-r t} f_{11} m_{1}\left(\gamma_{13}+\beta_{13} r_{13}(t)+\beta_{23} r_{23}(t)\right)\left(1-r_{12}(t)-r_{13}(t)\right) \phi_{13} \times \\
& \left(\left(P_{3}(t)-c_{3}(t)\right)-2 D_{13}(t)+\frac{\mu_{2} e^{-r t}}{f_{11} m_{1}}\right) \\
& -e^{-r t}\left(p_{11}+q_{11} f_{11}(t)\right)\left(1-f_{11}(t)-f_{12}(t)-f_{13}(t)\right)\left(1-\theta_{11} P_{1}(t)\right) m_{1} r_{13} \\
& D_{13}(t)=\frac{1}{2}\left(\left(P_{3}(t)-c_{3}(t)\right)+\frac{\mu_{2} e^{r t}}{f_{11} m_{1}}\right) \\
& -\frac{\left(p_{11}+q_{11} f_{11}(t)\right)\left(1-f_{11}(t)-f_{12}(t)-f_{13}(t)\right)\left(1-\theta_{11} P_{1}(t)\right) r_{13}}{2 f_{11}\left(\gamma_{13}+\beta_{13} r_{13}(t)+\beta_{23} r_{23}(t)\right)\left(1-r_{12}(t)-r_{13}(t)\right) \phi_{13}} \\
& 0=e^{-r t}\left(f_{12} m_{1}+f_{22} m_{2}\right)\left(\gamma_{23}+\beta_{13} r_{13}(t)+\beta_{23} r_{23}(t)\right)\left(1-r_{23}(t)\right) \phi_{23} \times \\
& \left(\left(P_{3}(t)-c_{3}(t)\right)-2 D_{23}(t)+\frac{\mu_{3} e^{r t}}{\left(f_{12} m_{1}+f_{22} m_{2}\right)}\right) \\
& -e^{-r t}\left(p_{12}+q_{12} f_{12}(t)+q_{22} f_{22}(t)+b_{12} r_{12}(t) f_{11}(t)\right)\left(1-f_{11}(t)-f_{12}(t)-f_{13}(t)\right) \times \\
& \left(1-\theta_{12} P_{2}(t)\right) m_{1} r_{23}(t) \\
& -e^{-r t}\left(p_{22}+q_{12} f_{12}(t)+q_{22} f_{22}(t)+b_{12} r_{12}(t) f_{11}(t)\right)\left(1-f_{22}(t)-f_{23}(t)\right) \times \\
& \left(1-\theta_{22} P_{2}(t)\right) m_{2} r_{23}(t) \\
& D_{23}(t)=\frac{1}{2}\left(\left(P_{3}(t)-c_{3}(t)\right)+\frac{\mu_{3} e^{r t}}{\left(f_{12} m_{1}+f_{22} m_{2}\right)}\right) \\
& \frac{-\left(p_{12}+q_{12} f_{12}(t)+q_{22} f_{22}(t)+b_{12} r_{12}(t) f_{11}(t)\right)\left(1-f_{11}(t)-f_{12}(t)-f_{13}(t)\right)\left(1-\theta_{12} P_{2}(t)\right) m_{1} r_{23}(t)}{2\left(f_{12} m_{1}+f_{22} m_{2}\right)\left(\gamma_{23}+\beta_{13} r_{13}(t)+\beta_{23} r_{23}(t)\right)\left(1-r_{23}(t)\right) \phi_{23}} \\
& \frac{-\left(p_{22}+q_{12} f_{12}(t)+q_{22} f_{22}(t)+b_{12} r_{12}(t) f_{11}(t)\right)\left(1-f_{22}(t)-f_{23}(t)\right)\left(1-\theta_{22} P_{2}(t)\right) m_{2} r_{23}(t)}{2\left(f_{12} m_{1}+f_{22} m_{2}\right)\left(\gamma_{23}+\beta_{13} r_{13}(t)+\beta_{23} r_{23}(t)\right)\left(1-r_{23}(t)\right) \phi_{23}}
\end{aligned}
$$

The state variables and multipliers are obtained from the following Boundary Value Problem: 


$$
\begin{aligned}
\dot{\lambda}_{1}= & -e^{-r t}\left(q_{11}\left(1-f_{11}(t)-f_{12}(t)-f_{13}(t)\right)-p_{11}-q_{11} f_{11}(t)\right)\left(1-\theta_{11} P_{1}(t)\right) \times \\
& \left(m_{1}\left(P_{1}(t)-c_{1}(t)+r_{12}\left(P_{2}(t)-c_{2}(t)-D_{12}(t)\right)+r_{13}\left(P_{3}(t)-c_{3}(t)-D_{13}(t)\right)\right)+\lambda_{1} e^{r t}\right) \\
& -e^{-r t}\left(b_{12} r_{12}(t)\left(1-f_{11}(t)-f_{12}(t)-f_{13}(t)\right)-\left(p_{12}+q_{12} f_{12}(t)+q_{22} f_{22}(t)+b_{12} r_{12}(t) f_{11}(t)\right)\right) \times \\
& \left(1-\theta_{12} P_{2}(t)\right)\left(m_{1}\left(P_{2}(t)-c_{2}(t)+r_{23}\left(P_{3}(t)-c_{3}(t)-D_{23}(t)\right)\right)+\lambda_{2} e^{r t}\right) \\
& -e^{-r t}\left(b_{13} r_{13}(t)\left(1-f_{11}(t)-f_{12}(t)-f_{13}(t)\right)-\right. \\
& \left.\left(p_{13}+q_{13} f_{13}(t)+q_{23} f_{23}(t)+q_{33} f_{33}(t)+b_{13} r_{13}(t) f_{11}(t)+b_{23} r_{23}(t)\left(f_{12}(t)+f_{22}(t)\right)\right)\right) \times \\
& \left(1-\theta_{13} P_{3}(t)\right)\left(m_{1}\left(P_{3}(t)-c_{3}(t)\right)+\lambda_{3} e^{r t}\right) \\
& -e^{-r t} b_{12} r_{12}(t)\left(1-f_{22}(t)-f_{23}(t)\right)\left(1-\theta_{22} P_{2}(t)\right) \times \\
& \left(m_{2}\left(P_{2}(t)-c_{2}(t)+r_{23}\left(P_{3}(t)-c_{3}(t)-D_{23}(t)\right)\right)+\lambda_{4} e^{r t}\right) \\
& -e^{-r t} b_{13} r_{13}(t)\left(1-f_{22}(t)-f_{23}(t)\right)\left(1-\theta_{23} P_{3}(t)\right)\left(m_{2}\left(P_{3}(t)-c_{3}(t)\right)+\lambda_{5} e^{r t}\right) \\
& -e^{-r t} b_{13} r_{13}(t)\left(1-f_{33}(t)\right)\left(1-\theta_{33} P_{3}(t)\right)\left(m_{3}\left(P_{3}(t)-c_{3}(t)\right)+\lambda_{6} e^{r t}\right) \\
& -e^{-r t} m_{1}\left(\gamma_{12}+\beta_{12} r_{12}(t)\right)\left(1-r_{12}(t)-r_{13}(t)\right) \phi_{12} D_{12}(t)\left(P_{2}(t)-c_{2}(t)-D_{12}(t)\right) \\
& -e^{-r t} m_{1}\left(\gamma_{13}+\beta_{13} r_{13}(t)+\beta_{23} r_{23}(t)\right)\left(1-r_{12}(t)-r_{13}(t)\right) \phi_{13} D_{13}(t)\left(P_{3}(t)-c_{3}(t)-D_{13}(t)\right)
\end{aligned}
$$

$$
\begin{aligned}
\dot{\lambda}_{2}= & e^{-r t}\left(p_{11}+q_{11} f_{11}(t)\right)\left(1-\theta_{11} P_{1}(t)\right) \times \\
& \left(m_{1}\left(P_{1}(t)-c_{1}(t)+r_{12}\left(P_{2}(t)-c_{2}(t)-D_{12}(t)\right)+r_{13}\left(P_{3}(t)-c_{3}(t)-D_{13}(t)\right)\right)+\lambda_{1} e^{r t}\right) \\
& -e^{-r t}\left(q_{12}\left(1-f_{11}(t)-f_{12}(t)-f_{13}(t)\right)-\left(p_{12}+q_{12} f_{12}(t)+q_{22} f_{22}(t)+b_{12} r_{12}(t) f_{11}(t)\right)\right) \times \\
& \left(1-\theta_{12} P_{2}(t)\right)\left(m_{1}\left(P_{2}(t)-c_{2}(t)+r_{23}\left(P_{3}(t)-c_{3}(t)-D_{13}(t)\right)\right)+\lambda_{2} e^{r t}\right) \\
& -e^{-r t}\left(b_{23} r_{23}(t)\left(1-f_{11}(t)-f_{12}(t)-f_{13}(t)\right)-\right. \\
& \left.\left(p_{13}+q_{13} f_{13}(t)+q_{23} f_{23}(t)+q_{33} f_{33}(t)+b_{13} r_{13}(t) f_{11}(t)+b_{23} r_{23}(t)\left(f_{12}(t)+f_{22}(t)\right)\right)\right) \times \\
& \left(1-\theta_{13} P_{3}(t)\right)\left(m_{1}\left(P_{3}(t)-c_{3}(t)\right)+\lambda_{3} e^{r t}\right) \\
& -e^{-r t} q_{12}\left(1-f_{22}(t)-f_{23}(t)\right)\left(1-\theta_{22} P_{2}(t)\right) \times \\
& \left(m_{2}\left(P_{2}(t)-c_{2}(t)+r_{23}\left(P_{3}(t)-c_{3}(t)-D_{23}(t)\right)\right)+\lambda_{4} e^{r t}\right) \\
& -e^{-r t} b_{23} r_{23}(t)\left(1-f_{22}(t)-f_{23}(t)\right)\left(1-\theta_{23} P_{3}(t)\right)\left(m_{2}\left(P_{3}(t)-c_{3}(t)\right)+\lambda_{5} e^{r t}\right) \\
& -e^{-r t} b_{23} r_{23}(t)\left(1-f_{33}(t)\right)\left(1-\theta_{33} P_{3}(t)\right)\left(m_{3}\left(P_{3}(t)-c_{3}(t)\right)+\lambda_{6} e^{r t}\right) \\
& -e^{-r t} m_{1}\left(\gamma_{23}+\beta_{13} r_{13}(t)+\beta_{23} r_{23}(t)\right)\left(1-r_{23}(t)\right) \phi_{23} D_{23}(t)\left(P_{3}(t)-c_{3}(t)-D_{23}(t)\right)
\end{aligned}
$$

$\dot{\lambda}_{3}=e^{-r t}\left(p_{11}+q_{11} f_{11}(t)\right)\left(1-\theta_{11} P_{1}(t)\right) \times$

$\left(m_{1}\left(P_{1}(t)-c_{1}(t)+r_{12}\left(P_{2}(t)-c_{2}(t)-D_{12}(t)\right)+r_{13}\left(P_{3}(t)-c_{3}(t)-D_{13}(t)\right)\right)+\lambda_{1} e^{r t}\right)$$$
+e^{-r t}\left(p_{12}+q_{12} f_{12}(t)+q_{22} f_{22}(t)+b_{12} r_{12}(t) f_{11}(t)\right)\left(1-\theta_{12} P_{2}(t)\right) \times
$$$$
\left(m_{1}\left(P_{2}(t)-c_{2}(t)+r_{23}\left(P_{3}(t)-c_{3}(t)-D_{13}(t)\right)\right)+\lambda_{2} e^{r t}\right)
$$$$
-e^{-r t}\left(q_{13}\left(1-f_{11}(t)-f_{12}(t)-f_{13}(t)\right)-\right.
$$$$
\left.\left(p_{13}+q_{13} f_{13}(t)+q_{23} f_{23}(t)+q_{33} f_{33}(t)+b_{13} r_{13}(t) f_{11}(t)+b_{23} r_{23}(t)\left(f_{12}(t)+f_{22}(t)\right)\right)\right) \times
$$$$
\left(1-\theta_{13} P_{3}(t)\right)\left(m_{1}\left(P_{3}(t)-c_{3}(t)\right)+\lambda_{3} e^{r t}\right)
$$$$
-e^{-r t} q_{13}\left(1-f_{22}(t)-f_{23}(t)\right)\left(1-\theta_{23} P_{3}(t)\right)\left(m_{2}\left(P_{3}(t)-c_{3}(t)\right)+\lambda_{5} e^{r t}\right)
$$$$
-e^{-r t} q_{13}\left(1-f_{33}(t)\right)\left(1-\theta_{33} P_{3}(t)\right)\left(m_{3}\left(P_{3}(t)-c_{3}(t)\right)+\lambda_{6} e^{r t}\right)
$$ 


$$
\begin{aligned}
& \dot{\lambda}_{4}=\quad-e^{-r t} q_{22}\left(1-f_{11}(t)-f_{12}(t)-f_{13}(t)\right)\left(1-\theta_{12} P_{2}(t)\right) \times \\
& \left(m_{1}\left(P_{2}(t)-c_{2}(t)+r_{23}\left(P_{3}(t)-c_{3}(t)-D_{23}(t)\right)\right)+\lambda_{2} e^{r t}\right) \\
& -e^{-r t} b_{23} r_{23}(t)\left(1-f_{11}(t)-f_{12}(t)-f_{13}(t)\right)\left(1-\theta_{13} P_{3}(t)\right)\left(m_{1}\left(P_{3}(t)-c_{3}(t)\right)+\lambda_{3} e^{r t}\right) \\
& -e^{-r t}\left(q_{22}\left(1-f_{22}(t)-f_{23}(t)\right)-\left(p_{22}+q_{12} f_{12}(t)+q_{22} f_{22}(t)+b_{12} r_{12}(t) f_{11}(t)\right)\right) \times \\
& \left(1-\theta_{22} P_{2}(t)\right)\left(m_{2}\left(P_{2}(t)-c_{2}(t)+r_{23}\left(P_{3}(t)-c_{3}(t)-D_{23}(t)\right)\right)+\lambda_{4} e^{r t}\right) \\
& -e^{-r t}\left(b_{23} r_{23}(t)\left(1-f_{22}(t)-f_{23}(t)\right)-\right. \\
& \left.\left(p_{23}+q_{13} f_{13}(t)+q_{23} f_{23}(t)+q_{33} f_{33}(t)+b_{13} r_{13}(t) f_{11}(t)+b_{23} r_{23}(t)\left(f_{12}(t)+f_{22}(t)\right)\right)\right) \times \\
& \left(1-\theta_{23} P_{3}(t)\right)\left(m_{2}\left(P_{3}(t)-c_{3}(t)\right)+\lambda_{5} e^{r t}\right) \\
& -e^{-r t} b_{23} r_{23}(t)\left(1-f_{33}(t)\right)\left(1-\theta_{33} P_{3}(t)\right)\left(m_{3}\left(P_{3}(t)-c_{3}(t)\right)+\lambda_{6} e^{r t}\right) \\
& -e^{-r t} m_{2}\left(\gamma_{23}+\beta_{13} r_{13}(t)+\beta_{23} r_{23}(t)\right)\left(1-r_{23}(t)\right) \phi_{23} D_{23}(t)\left(P_{3}(t)-c_{3}(t)-D_{23}(t)\right) \\
& \dot{\lambda}_{5}=\quad-e^{-r t} q_{23}\left(1-f_{11}(t)-f_{12}(t)-f_{13}(t)\right)\left(1-\theta_{13} P_{3}(t)\right)\left(m_{1}\left(P_{3}(t)-c_{3}(t)\right)+\lambda_{3} e^{r t}\right) \\
& +e^{-r t}\left(p_{22}+q_{12} f_{12}(t)+q_{22} f_{22}(t)+b_{12} r_{12}(t) f_{11}(t)\right)\left(1-\theta_{22} P_{2}(t)\right) \times \\
& \left(m_{2}\left(P_{2}(t)-c_{2}(t)+r_{23}\left(P_{3}(t)-c_{3}(t)-D_{23}(t)\right)\right)+\lambda_{4} e^{r t}\right) \\
& -e^{-r t}\left(q_{23}\left(1-f_{22}(t)-f_{23}(t)\right)-\right. \\
& \left.\left(p_{23}+q_{13} f_{13}(t)+q_{23} f_{23}(t)+q_{33} f_{33}(t)+b_{13} r_{13}(t) f_{11}(t)+b_{23} r_{23}(t)\left(f_{12}(t)+f_{22}(t)\right)\right)\right) \times \\
& \left(1-\theta_{23} P_{3}(t)\right)\left(m_{2}\left(P_{3}(t)-c_{3}(t)\right)+\lambda_{5} e^{r t}\right) \\
& -e^{-r t} q_{23}\left(1-f_{33}(t)\right)\left(1-\theta_{33} P_{3}(t)\right)\left(m_{3}\left(P_{3}(t)-c_{3}(t)\right)+\lambda_{6} e^{r t}\right) \\
& \dot{\lambda}_{6}=\quad-e^{-r t} q_{33}\left(1-f_{11}(t)-f_{12}(t)-f_{13}(t)\right)\left(1-\theta_{13} P_{3}(t)\right)\left(m_{1}\left(P_{3}(t)-c_{3}(t)\right)+\lambda_{3} e^{r t}\right) \\
& -e^{-r t} q_{33}\left(1-f_{22}(t)-f_{23}(t)\right)\left(1-\theta_{23} P_{3}(t)\right)\left(m_{2}\left(P_{3}(t)-c_{3}(t)\right)+\lambda_{5} e^{r t}\right) \\
& -e^{-r t}\left(q_{33}\left(1-f_{33}(t)\right)-\right. \\
& \left.\left(p_{33}+q_{13} f_{13}(t)+q_{23} f_{23}(t)+q_{33} f_{33}(t)+b_{13} r_{13}(t) f_{11}(t)+b_{23} r_{23}(t)\left(f_{12}(t)+f_{22}(t)\right)\right)\right) \times \\
& \left(1-\theta_{33} P_{3}(t)\right)\left(m_{3}\left(P_{3}(t)-c_{3}(t)\right)+\lambda_{6} e^{r t}\right) \\
& \dot{\mu}_{1}=-e^{-r t}\left(\beta_{12}\left(1-r_{12}(t)-r_{13}(t)\right)-\left(\gamma_{12}+\beta_{12} r_{12}(t)\right)\right) \phi_{12} D_{12}(t) \times \\
& \left(f_{11} m_{1}\left(P_{2}(t)-c_{2}(t)-D_{12}(t)\right)+\mu_{1} e^{r t}\right) \\
& +e^{-r t}\left(\gamma_{13}+\beta_{13} r_{13}(t)+\beta_{23} r_{23}(t)\right) \phi_{13} D_{13}(t)\left(f_{11} m_{1}\left(P_{3}(t)-c_{3}(t)-D_{13}(t)\right)+\mu_{2} e^{r t}\right) \\
& -e^{-r t}\left(p_{11}+q_{11} f_{11}(t)\right)\left(1-f_{11}(t)-f_{12}(t)-f_{13}(t)\right)\left(1-\theta_{11} P_{1}(t)\right) m_{1}\left(P_{2}(t)-c_{2}(t)-D_{12}(t)\right) \\
& -e^{-r t} b_{12} f_{11}(t)\left(1-f_{11}(t)-f_{12}(t)-f_{13}(t)\right)\left(1-\theta_{12} P_{2}(t)\right) \times \\
& \left(m_{1}\left(P_{2}(t)-c_{2}(t)+r_{23}\left(P_{3}(t)-c_{3}(t)-D_{23}(t)\right)\right)+\lambda_{2} e^{r t}\right) \\
& -e^{-r t} b_{12} f_{11}(t)\left(1-f_{22}(t)-f_{23}(t)\right)\left(1-\theta_{22} P_{2}(t)\right) \times \\
& \left(m_{2}\left(P_{2}(t)-c_{2}(t)+r_{23}\left(P_{3}(t)-c_{3}(t)-D_{23}(t)\right)\right)+\lambda_{4} e^{r t}\right)
\end{aligned}
$$




$$
\begin{aligned}
& \dot{\mu}_{2}=e^{-r t}\left(\gamma_{12}+\beta_{12} r_{12}(t)\right) \phi_{12} D_{12}(t)\left(f_{11} m_{1}\left(P_{2}(t)-c_{2}(t)-D_{12}(t)\right)+\mu_{1} e^{r t}\right) \\
& -e^{-r t}\left(\beta_{13}\left(1-r_{12}(t)-r_{13}(t)\right)-\left(\gamma_{13}+\beta_{13} r_{13}(t)+\beta_{23} r_{23}(t)\right)\right) \phi_{13} D_{13}(t) \times \\
& \left(f_{11} m_{1}\left(P_{3}(t)-c_{3}(t)-D_{13}(t)\right)+\mu_{2} e^{r t}\right) \\
& -e^{-r t} \beta_{13}\left(1-r_{23}(t)\right) \phi_{23} D_{23}(t)\left(\left(f_{12} m_{1}+f_{22} m_{2}\right)\left(P_{3}(t)-c_{3}(t)-D_{23}(t)\right)+\mu_{3} e^{r t}\right) \\
& -e^{-r t}\left(p_{11}+q_{11} f_{11}(t)\right)\left(1-f_{11}(t)-f_{12}(t)-f_{13}(t)\right)\left(1-\theta_{11} P_{1}(t)\right) m_{1}\left(P_{3}(t)-c_{3}(t)-D_{13}(t)\right) \\
& -e^{-r t} b_{13} f_{11}(t)\left(1-f_{11}(t)-f_{12}(t)-f_{13}(t)\right)\left(1-\theta_{13} P_{3}(t)\right)\left(m_{1}\left(P_{3}(t)-c_{3}(t)\right)+\lambda_{3} e^{r t}\right) \\
& -e^{-r t} b_{13} f_{11}(t)\left(1-f_{22}(t)-f_{23}(t)\right)\left(1-\theta_{23} P_{3}(t)\right)\left(m_{2}\left(P_{3}(t)-c_{3}(t)\right)+\lambda_{5} e^{r t}\right) \\
& -e^{-r t} b_{13} f_{11}(t)\left(1-f_{33}(t)\right)\left(1-\theta_{33} P_{3}(t)\right)\left(m_{3}\left(P_{3}(t)-c_{3}(t)\right)+\lambda_{6} e^{r t}\right) \\
& \dot{\mu}_{3}=\quad-e^{-r t} \beta_{23}\left(1-r_{12}(t)-r_{13}(t)\right) \phi_{13} D_{13}(t)\left(f_{11} m_{1}\left(P_{3}(t)-c_{3}(t)-D_{13}(t)\right)+\mu_{2} e^{r t}\right) \\
& -e^{-r t}\left(\beta_{23}\left(1-r_{23}(t)\right)-\left(\gamma_{23}+\beta_{13} r_{13}(t)+\beta_{23} r_{23}(t)\right)\right) \phi_{23} D_{23}(t) \times \\
& \left(\left(f_{12} m_{1}+f_{22} m_{2}\right)\left(P_{3}(t)-c_{3}(t)-D_{23}(t)\right)+\mu_{3} e^{r t}\right) \\
& -e^{-r t}\left(\left(p_{12}+q_{12} f_{12}(t)+q_{22} f_{22}(t)+b_{12} r_{12}(t) f_{11}(t)\right)\left(1-f_{11}(t)-f_{12}(t)-f_{13}(t)\right) \times\right. \\
& \left(1-\theta_{12} P_{2}(t)\right) m_{1}+\left(1-\theta_{22} P_{2}(t)\right) m_{2} \times \\
& \left.\left(p_{22}+q_{12} f_{12}(t)+q_{22} f_{22}(t)+b_{12} r_{12}(t) f_{11}(t)\right)\left(1-f_{22}(t)-f_{23}(t)\right)\right) \times \\
& \left(P_{3}(t)-c_{3}(t)-D_{23}(t)\right) \\
& -e^{-r t} b_{23}\left(f_{12} m_{1}+f_{22} m_{2}\right)\left(1-f_{11}(t)-f_{12}(t)-f_{13}(t)\right)\left(1-\theta_{13} P_{3}(t)\right) \times \\
& \left(m_{1}\left(P_{3}(t)-c_{3}(t)\right)+\lambda_{3} e^{r t}\right) \\
& -e^{-r t} b_{23}\left(f_{12} m_{1}+f_{22} m_{2}\right)\left(1-f_{22}(t)-f_{23}(t)\right)\left(1-\theta_{23} P_{3}(t)\right)\left(m_{2}\left(P_{3}(t)-c_{3}(t)\right)+\lambda_{5} e^{r t}\right) \\
& -e^{-r t} b_{23}\left(f_{12} m_{1}+f_{22} m_{2}\right)\left(1-f_{33}(t)\right)\left(1-\theta_{33} P_{3}(t)\right)\left(m_{3}\left(P_{3}(t)-c_{3}(t)\right)+\lambda_{6} e^{r t}\right)
\end{aligned}
$$

For the scenario when the upgrade-rebate program is not implemented, the optimal control problem is a special case of the previous example where

$$
\begin{aligned}
\dot{r}_{12} & =0, \dot{r}_{13}=0, \dot{r}_{23}=0 \\
D_{12} & =0, D_{13}=0, D_{23}=0 \\
\dot{\mu}_{1} & =0, \dot{\mu}_{2}=0, \dot{\mu}_{3}=0
\end{aligned}
$$

